\title{
Sobre la limitación de responsabilidad en el derecho de sociedades y su posible extensión en el contexto de la modernización
}

\author{
María Fernanda Vásquez Palma*
}

\section{RESUMEN}

El presente artículo se centra en el análisis de la extensión del privilegio de la responsabilidad limitada en el contexto de la modernización del Derecho societario. Se analizan los fundamentos de su creación y posterior expansión, su conexión con la redefinición de la personalidad jurídica y la búsqueda de mecanismos adecuados de control.

Limitación de responsabilidad - Extensión - Derecho de sociedades

\section{On the release of Liability in Corporate Law and its possible extension in the context of modernisation}

\begin{abstract}
This article focuses on the analysis of the extension of the privilege of limited liability in the context of the modernization of company law; analyzing the foundations of its creation and subsequent expansion, its connection with the redefinition of legal personality, and the search for suitable control mechanisms.
\end{abstract}

Limitation of liability - Extension - Company law

* Doctora en Derecho por la Universidad Complutense de Madrid. Profesora Derecho Privado, Facultad de Ciencias Jurídicas y Sociales, Universidad de Talca. Email: mfvasquez@utalca.cl.

** Este artículo se enmarca en el proyecto de investigación Fondecyt regular $\mathrm{N}^{\circ} 1130376$, titulado La modernización del Derecho societario en Chile: Un análisis sincrónico a partir de las políticas legislativas adoptadas en Derecho comparado, del que la autora es investigadora responsable. Se agradece al Fondo Nacional de Ciencia y Tecnología el apoyo a esta investigación.

Artículo recibido el 11 de febrero de 2014 y aceptado para su publicación por el Comité Editorial el 29 de octubre de 2014. 


\section{INTRODUCCIÓN}

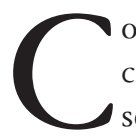

onstituye un hecho indubitado que toda institución jurídica plantea dogmas cuya interpelación es necesaria, pues a partir de su identificación y revisión se abren diferentes posibilidades de análisis y cambios $^{1}$. Si agregamos a ello que el Derecho societario se encuentra desde hace un par de décadas en un proceso evolutivo de modernización, llegaremos a la conclusión que nos encontramos en un escenario propicio para replantear diversos paradigmas existentes en la materia. El que nos proponemos abordar en estas líneas enlaza con la posible extensión de la limitación de la responsabilidad limitada como principio rector del Derecho societario, lo que nos invita a reflexionar -en el marco de una revisión tipológica- acerca de la extrapolación de este principio de manera general.

Lo primero que hemos de advertir es que si bien podría considerarse que las sociedades por gozar de personalidad jurídica protegen el patrimonio de los socios sobre la base del principio de separación o autonomía patrimonial, lo cierto es que ello no es del todo efectivo. Es la limitación de responsabilidad, muy posterior a la creación de la personalidad jurídica societaria, la que cumple esta función en los tipos societarios que así lo establecen. Ello liga con el desarrollo del Derecho societario y los factores económicos predominantes, pues al ser considerada la sociedad como un revestimiento jurídico de una empresa y, de este modo, como un instrumento de inversión, fue natural buscar una protección que fortaleciera este campo. En este contexto, si bien todos los tipos societarios creados con posterioridad a la época codificadora han consignado este principio, no se ha propiciado en nuestra doctrina una discusión sobre su posible extensión a las figuras societarias creadas con anterioridad al reconocimiento de este privilegio. Lo anterior es relevante, pues se vincula con un intento de reconstrucción de la noción de personalidad jurídica que ha quedado a medio camino y que se ha intentado superar por medio de la aplicación de la doctrina del levantamiento del velo. Nos detendremos también en ésta última en aras de determinar su necesidad y operatividad. La revisión de este recorrido, lejos de cualquier afán meramente histórico, se plantea con la intención de hallar en el elementos referentes a dónde asentar un mejor entendimiento y una interpretación fundada del Derecho societario chileno y los elementos que en él habitan.

A partir de lo anterior, esta investigación se centra fundamentalmente en la necesidad de replantear la extensión del privilegio de la responsabilidad limitada en el contexto de la modernización del Derecho societario, analizando de paso su conexión con la definición de personalidad jurídica, sus causas, fundamentos, consecuencias y la búsqueda de mecanismos adecuados de control. Siguiendo este orden de ideas, analizaremos en la primera parte de este texto aspectos relativos a la limitación de responsabilidad y personalidad jurídica en las sociedades; seguiremos con la revisión de la expansión de la limitación de responsabilidad limitada; en la tercera parte nos abocaremos a los posibles

${ }^{1}$ Relativo a esta materia, Lazo González, P., "Limitación de la responsabilidad: bases romanas de un dogma iusprivatista", en Revista de Derecho Universidad Austral de Chile, Vol. XXV - Julio 2012, pp. 7-24. 
abusos de la personalidad jurídica societaria y los mecanismos que los revierten; para finalizar con algunas propuestas a modo de conclusión.

\section{SOBRE LA LIMITACIÓN DE RESPONSABILIDAD Y LA PERSONIFICACIÓN EN LAS SOCIEDADES}

\section{Necesaria distinción entre la personalidad jurídica y la limitación de responsabilidad limitada}

El reconocimiento de la personalidad jurídica en el Derecho societario implica establecer un principio de separación entre la sociedad y sus miembros, la que se proyecta en dos dimensiones: jurídico-corporativo y patrimonial-financiera ${ }^{2}$; desde el primer ángulo, la sociedad actúa como un sujeto de derecho completamente independiente, es representado y tiene atributos propios (domicilio, capacidad, nombre, etc.); desde el segundo, la sociedad posee un activo y un pasivo organizado contablemente con un inventario y balance inicial, adscrito a un riesgo propio ${ }^{3}$. En este escenario, se considera al patrimonio social como una inversión procedente del exterior de la que se ha de rendir cuenta, cuyo fundamento mira al bien común o al interés general en cuanto busca salvaguardar dichos intereses, de manera que confiere seguridad a los inversores y acreedores ${ }^{4}$.

Bajo estos presupuestos, la personalidad jurídica se entiende en la actualidad como una técnica de organización patrimonial respecto de una o más personas, que surge por medio del reconocimiento jurídico de la titularidad de ciertos atributos, derechos subjetivos y obligaciones. Como consecuencia de esta atribución, el sujeto tendrá: 1) Un patrimonio propio, separado de los socios o integrantes, quienes enajenan a aquella sus aportaciones a cambio de participaciones sociales y que se encuentra adscrito al pago de los acreedores que han contratado con la sociedad; 2) Nombre o razón social, domicilio y nacionalidad propios; 3) Un estatuto legal integrado por derechos y obligaciones; 4) Capacidad de obrar que realiza por medio de sus representantes; 5) La titularidad de la empresa, pudiendo adquirir y transmitir bienes y derechos mediante negocios jurídicos a título singular o a título global (fusión, división, etc.); 6) Capacidad procesal para demandar y ser demandada ante los tribunales estatales y arbitrales; 7) Es, además, sujeto pasivo de sanciones administrativas e incluso penales frente a determinados supuestos 5 .

${ }^{2}$ En términos generales, la personalidad jurídica no se concede para la consecución de un fin, por lo que estos sujetos tienen, al igual que la persona natural, una capacidad jurídica general, Vicent Chuliá, F., Introducción al Derecho mercantil, Tirant lo Blanch, Valencia, 2006, p. 266.

${ }^{3}$ Este revestimiento nos permite distinguir entre sociedades externas e internas, dependiendo si se manifiestan o exteriorizan a la comunidad en razón de su especial estructura organizativa y, sobre todo, por la atribución del expediente técnico de la personalidad. Véase: Paz-Ares Rodríguez, C., "Atributos y límites a la personalidad jurídica”, en Uría R., Menéndez A. (Coord.), Curso de derecho mercantil I, Ed. Civitas, Madrid, 1999, p. 561.

${ }^{4}$ Quesada Sánchez, A., “Análisis histórico-jurídico del artículo 1669 del 'Código Civil' español”, en Revista de Derecho de la Pontificia Universidad Católica de Valparaíso, XXXII, $1^{\text {er }}$ semestre 2009, p. 169.

${ }^{5}$ Entre otros, véase: Vincent Chuliá, ob. cit. p. 266. 
Como señalamos, producto de la concesión de la personalidad jurídica se acostumbra a subrayar como elemento esencial el principio de autonomía o separación patrimonial entre la entidad y los miembros, tanto desde una perspectiva jurídica como patrimonial ${ }^{6}$, el que a su vez constituiría una excepción al principio de responsabilidad patrimonial universal $^{7}$ y del clásico dogma de la unidad e indivisibilidad del patrimonio, como atributo de la personalidad humana. Este principio implica, en principio, que los deberes, responsabilidades y derechos subjetivos le son conferidos a la sociedad de manera diferenciada de los miembros que la conforman ${ }^{8}$; esto quiere decir que de las obligaciones contraídas por la sociedad responde esta última con su patrimonio y no los socios, pues el tercero contrata con la sociedad como un sujeto de derechos independiente. Sin embargo, esta afirmación plantea en el Derecho societario matices más o menos intensos según el tipo social que se elija ${ }^{9}$, pues -como veremos- no todas las sociedades gozan de la misma protección.

En Chile ${ }^{10}$, por ejemplo, ciertos tipos societarios gozan de un claro hermetismo patrimonial (sociedad de responsabilidad limitada, sociedad anónima y sociedad por acciones $)^{11}$, pero en el resto de las sociedades la situación cambia indudablemente. Así, en la sociedad colectiva los socios deben responder de las deudas sociales y la quiebra de aquella trae como consecuencia la de los socios individualmente ${ }^{12}$. Lo mismo acontece con las sociedades en comanditas respecto de sus socios gestores, en tanto estos son indefinida y solidariamente responsables de todas las obligaciones y pérdidas de la sociedad; el socio comanditario, en cambio, solo responde hasta la concurrencia de sus aportes prometidos o entregados, a menos que permitan o toleren la inserción de su nombre en la razón social (Art. 483 CCo.) o ejecuten actos de administración social (Art. 484 CCo.), casos en que serán considerados responsables de todas las pérdidas y

\footnotetext{
${ }^{6}$ Nuestra legislación reconoce el principio de separación patrimonial en el Art. 549 del CC. A partir de ello, se desprende que la personalidad jurídica se construye sobre esta separación entre entidad y miembros, y se conforma a su vez de dos elementos: a) La imputación diferenciada de actos, derechos y responsabilidades, y b) La aplicación de las normas jurídicas con independencia del sustrato personal de las entidades morales. Respecto de las sociedades, el principio de separación se reconoce en el Art. 2053 del CC, al establecer que la sociedad forma una persona jurídica distinta a los miembros que la integran.

${ }^{7}$ Véase: Art. 2465 CC.

${ }^{8}$ Lojendio Osborne, I.; Núñez Lozano, P., "Las sociedades mercantiles”, en Jiménez Sánchez, G., Derecho mercantil I, Ed. Marcial Pons, 2010, p. 16-17.

${ }^{9}$ Sánchez Calero, F., Instituciones de derecho mercantil, Ed. Edersa, (17º ed.), Madrid, 1994, pp. 238-239.

${ }^{10}$ Sobre esta materia puede consultarse, entre otros: Sandoval López, R., Derecho comercial. Sociedades de personas y de capital, tomo I y II, Ed. Jurídica de Chile, Santiago de Chile, 2003; Vásquez Palma, M. F., Sociedades, Ed. Thomson Reuters, Santiago de Chile, 2013; Puelma Acorssi, A., Sociedades, Ed. Jurídica de Chile, Santiago de Chile, 2006; Torres Zagal, O., Derecho de sociedades, $3^{\text {ra }}$ edición actualizada, LegalPublishing, Chile, 2008; Puga Vial, J., La sociedad anónima y otras sociedades por acciones en el Derecho chileno y comparado, Ed. Jurídica de Chile, Santiago, 2011.

${ }^{11}$ Art. $2^{\circ}$ Ley 3.918; Art. 424 Cco.; Art. $1^{\circ}$ LSA.

12 Véase: Arts. 2094, 2095 Código Civil, 370 del Código de Comercio, Art. 46 Libro IV Código de Comercio.
} 
obligaciones de la sociedad. De este modo, si bien se concede personalidad jurídica a todas las sociedades (Art. 2053 CC), no todas gozan del mismo estatus ${ }^{13}$.

Esto nos lleva a preguntarnos si esto liga con el diseño de la personalidad jurídica o con otros factores. En otras palabras ¿Tiene la personalidad jurídica distinto alcance respecto de los tipos societario?, ¿Qué justifica esta diferenciación en la carga obligacional de los socios respecto de las deudas sociales? La razón reside en la creación de la "limitación de la responsabilidad" que se erige con posterioridad al nacimiento de la personalidad jurídica, de manera que no se trata de una consecuencia de esta, sino de un instituto independiente que se encuentra vinculado a razones fundamentalmente económicas $^{14}$ y no contractuales. De este modo, las diferencias que habitan acerca de esta materia se deben a las características intrínsecas de cada tipo societario en particular y su construcción legislativa, y no al dato extrínseco de la presencia o ausencia de personalidad jurídica ${ }^{15}$.

Llegados a este punto, es preciso reconocer que las barreras tradicionales de la personalidad jurídica han ido cediendo por razones prácticas venidas del desarrollo económico, y es en este contexto donde la expansión del régimen de limitación de responsabilidad se ha vuelto un eje central apetecido por todas las nuevas construcciones tipológicas societarias. Bajo estas circunstancias, la responsabilidad limitada se ofrece como un dogma ${ }^{16}$, una construcción cuya existencia dejó de ser objeto de revisión en los distintos sistemas jurídicos modernos y que se concibe como una característica de las inversiones en general.

Siguiendo esta ilación, la responsabilidad limitada de los socios no puede ser confundida con el principio de la división patrimonial nacido de la personalidad jurídica, a pesar de que en algunos sistemas, como en el alemán, ambas características se presenten en forma simultánea. La concesión de personalidad no implica la impermeabilidad del patrimonio de los socios frente a las deudas sociales ${ }^{17}$, ello solo lo logra el principio de limitación de responsabilidad limitada. A partir de ello, el hermetismo patrimonial que nace de la limitación de responsabilidad vino a modificar, en alguna medida, el paradigma del Derecho societario y de la propia noción de persona jurídica, en cuanto se comenzó a ver a la sociedad personificada como un mecanismo de emprendimiento al servicio de los particulares.

\footnotetext{
${ }^{13}$ Reconociendo lo anterior, se pronunció la Corte Suprema el 7 de junio de 2007, en causa Inversiones Fabjanovic Ltda. con Comercial Araucaria y otros. En un sentido similar, la Corte Suprema, el 6 de abril de 2009, en causa Verónica Fernández Omar contra Sociedad Miguel y Miguelo's Pub Limitada.

${ }^{14}$ Sobre los aspectos históricos véase, Lazo González, ob. cit., pp. 7-24.

15 Aguirre, H., "El debate sobre la personalidad jurídica de las sociedades de persona en Italia", disponible en http://nvabogados.com.ar/El\%20debate\%20sobre\%20la\%20personalidad\%20juridica\%20 de\%20las\%20sociedades\%20en\%20Italia.pdf p. 11.

${ }^{16}$ Lazo, op. cit., pp. 7-24.

17 Véase: Hugo Richard, E., "Personalidad jurídica. Inoponibilidad”, en Nissen, R.; Pardini, M. y Vitolo, D. (directores), Responsabilidad y abuso en la actuación societaria, Ed. Ad Hoc, Buenos Aires, 2002.
} 


\section{Algunas notas históricas que debemos tener en consideración}

Como advertimos al inicio, el Derecho societario ha sido una institución especialmente evolutiva. Para comprender esta idea es preciso realizar un breve recorrido histórico con el objeto de determinar cómo se ha tratado esta materia en las distintas épocas de su desarrollo. En esta línea, sabido es que el Derecho romano no se reconocía a la sociedad personalidad jurídica, de manera tal que la idea de un patrimonio social distinto de los socios era ajena ${ }^{18}$, a lo sumo existían ciertas características que presentaban alguna similitud con las personas jurídicas (corpore), como la facultad de adquirir bienes y administrarlos (sociedades vectigalum o sociedades de republicanos), mas no una autonomía patrimonial. El contrato constitutivo de sociedad se estimaba como un vínculo puramente interno que daba origen a obligaciones entre los socios y que no creaba un ente titular de derechos diferenciado. Se entendía que existía un mandato entre ellos en donde quedaban solidaria e ilimitadamente obligados entre si $1^{19}$.

Fue con posterioridad, en plena época del predominio del carácter absolutista del Estado, bajo la influencia de los escolásticos y ius naturalistas, que se comenzó a elaborar la tesis de la persona moral amparada en el Derecho natural e internacional ${ }^{20}$. La noción de persona jurídica de las sociedades se afianza de la mano de la Revolución Francesa, Códigos napoleónicos y la Escuela histórica del Derecho dirigida por Savigny, de gran influencia en el derecho alemán ${ }^{21}$, al comprender que esta última no era la suma de

18 Se consideraban personas civiles las grandes sociedades creadas para la explotación de las rentas públicas, como las sociedades de publicanos y las dedicadas a la explotación de las minas de oro y plata y las salinas (Gayo, en D. 3, 4, 1: "Los que pueden constituirse como colegio, sociedad o cualquier otra corporación, tienen, como si fueran una ciudad, bienes comunes, caja común y un apoderado o síndico, por medio de quien, como en una ciudad, se trate y haga lo que deba tratarse y hacerse en común" [El Digesto de Justiniano [traducción de Álvaro d'Ors y otros, Pamplona, Aranzadi, 1968), p. 157] en Quesada Sánchez, ob. cit., p. 134.

${ }^{19}$ Miranda Ostegaard, D., "El traspaso del velo corporativo en los convenios concursales", en Revista de Derecho de la Empresa, No 9, enero-marzo 2007, pp. 84 y 85.

${ }^{20}$ Como institución, la personalidad jurídica tiene larga data, cada siglo ha ido marcando su desarrollo. Primero se le trató como una institución administrativa y luego como verdaderos sujetos de derecho con separación absoluta de las personas naturales que la integran. Véase: Lyon Puelma, A., Personas jurídicas, Ed. Universidad Católica de Chile, Santiago de Chile, 2002, pp. 23-24; Ferrara, F., Teoría de la persona jurídica, Editorial Comares, España, 2006, pp. 136 y ss.

${ }^{21}$ Distintas teorías han intentado explicar la naturaleza jurídica de dichos sujetos, el respaldo que ellas logren en una legislación modela el especial entendimiento que adquiere este sujeto para dicho ordenamiento jurídico. Entre ellas destacan la tesis de la ficción de Savigny que sostiene que la personalidad jurídica es una creación del ordenamiento jurídico, ya sea por una necesidad real o creada. La teoría de Ihering, que parte de la base que todo derecho privado existe para asegurar al hombre una ventaja cualquiera, venir en ayuda de sus necesidades, salvaguardar sus intereses y concurrir al cumplimiento de los fines de la vida, de tal manera que la persona jurídica sería un mecanismo, un intermediario artificial que permite asegurar el goce de los individuos aislados o sujetos indeterminados. La teoría de los patrimonios reservados fue elaborada por Brinz y Bekker, para ellos sí se parte de la idea inicial de Ihering. Esta teoría acentúa la idea del fin en cuanto punto central en torno al que viene a constituirse el patrimonio, pero no logra explicar por sí solo el sustrato de la personalidad jurídica. La teoría de Kelsen proclama que el concepto de persona solo designa un haz de obligaciones, de responsabilidades y de derechos subjetivos o un conjunto de normas. La persona jurídica se convierte en un centro de imputación de actos, derechos y obligaciones, es decir, una entidad ficticia 
los socios sino que estaba por encima de los sujetos que la conformaban, rebasando su personalidad física; adicionalmente, se hizo necesaria su configuración para explicar las relaciones que se originaban entre la sociedad y los terceros. Su fundamento se encontraría en el bien común o interés general, al conferir seguridad a los inversores por un medio técnico que permitía diferenciar patrimonios, derechos, obligaciones y responsabilidades.

El concepto de persona jurídica, tal y como ha llegado a nuestros días, es obra de la construcción de la categoría de "Derecho subjetivo" y la necesidad de dilucidar el tipo de titularidad que corresponde a los miembros de una corporación referente a los bienes y derechos destinados a la consecución de fines corporativos la posicionan al lado de la persona física, como otra especie perteneciente al género sujetos de derechos. Esta evolución llega a su punto más álgido con la aceptación por la legislación de las ideas del "formalismo jurídico" que establece como único presupuesto necesario para la existencia de la misma, la legitimidad de su acto constitutivo o fundacional. En otras palabras, los entes dotados de personalidad jurídica se consideran -al igual que al hombre- sujetos de derechos subjetivos y relaciones jurídicas autónomas ajenos a las personas que la integran. Con ello, se produce el paso relevante al afirmar que la persona jurídica -en cuanto creación del Derecho objetivo- solo requiere del reconocimiento legislativo para ser considerada como tal ${ }^{22}$. En la actualidad, la personalidad jurídica constituye la vestidura orgánica con la que la sociedad actúa ante la vida del derecho, cuyo fundamento reside en el interés de cumplir con el objeto social y de garantizar a los terceros el cumplimiento de las obligaciones nacidas a partir de la actividad realizada, generando un centro de imputación (persona o preferencias) diferenciado, en cuanto unidad económica funcional ${ }^{23}$.

Otro paso relevante en el desarrollo de esta noción deriva del posterior nacimiento de la institución de la responsabilidad limitada. En efecto, el apogeo del comercio y de las relaciones comerciales, ya transoceánicas, reclamaba nuevas formas adecuadas a los tiempos y, en ese orden de cosas, el surgimiento de las nuevas sociedades de comercio resultó esencial para la construcción del concepto de personalidad jurídica. Esta tiene como antecedente inmediato las compañías creadas en los siglos XVI y XVII para el comercio de las Indias orientales y occidentales ${ }^{24}$, pues al amparo de tal privilegio, los

adonde deben ser referidas las acciones y las omisiones reguladas por las normas jurídicas. Por su parte, Von Gierke afirma que la sociedad es una persona real colectiva formada por hombres reunidos y organizados en una existencia corporativa que tiende a la consecución de fines que trascienden de la esfera de los intereses individuales, mediante la común y única fuerza de la voluntad y de acción. Por último, Ferrara señala que las personas jurídicas constituyen una realidad ideal jurídica y no una ficción. Para esta tesis, el término persona implica la de sujetos de derechos. Sobre esta materia, véase: Lyon Puelma, ob. cit., pp. 23-24; Ferrara, F., ob. cit., pp. 136 y ss.

${ }^{22}$ De los Mozos, J., "La evolución del concepto de persona jurídica en el derecho español", en Derecho civil, método, sistemas y categorías jurídicas, Ed. Civitas, Madrid, 1988, p. 246.; Boldó Roda, C., Levantamiento del velo y persona jurídica en el Derecho privado español, Ed. Thomson-Aranzadi, 4a edición, 2006, p. 40.

${ }^{23}$ Véase: Hugo Richard, ob. cit., pp. 263 a 324.

${ }^{24}$ En Holanda se creó en 1602 la Compañía de las Indias Orientales y en 1621 la Compañía de las Indias Occidentales; en Inglaterra, en 1612, la Compañía de las Indias Orientales y posteriormente lo mismo 
socios de estas compañías respondían de las deudas sociales únicamente con el capital aportado $^{25}$. Tales empresas ostentaban un carácter de Derecho público y participaban del poder soberano, de manera que la concesión de este privilegio al importe de las participaciones sociales se vio con buenos ojos al permitir la asunción de grandes riesgos de inversión que, de otro modo, habrían sido imposible de acometer.

Estas compañías fueron el antecedente inmediato de la sociedad anónima ${ }^{26}$, de manera que su especial filosofía se desplazó del campo del Derecho público al privado con finalidad lucrativa, lo que hizo necesario buscar una nueva justificación para mantener el aludido privilegio en esta sede. Es allí donde el concepto de persona jurídica vino en ayuda del mantenimiento de aquél y fue así como la inclusión de la sociedad anónima en la categoría de persona jurídica de Derecho privado cambió la fundamentación teórica de esta noción ${ }^{27}$. La nota que otrora se consideró esencial a la limitación, esto es, "un interés público permanente" 28 , fue abandonada y en su lugar se asentó la idea de la autonomía patrimonial y la insensibilidad entre los patrimonios de la sociedad y los socios, lo que llevaría a justificar, en mayor medida, la irresponsabilidad de los socios por las deudas sociales. Las causas de ello radican en los fundamentos económicos y políticos que se tuvieron presentes; respecto de la primera se pensó que si la limitación de responsabilidad había demostrado ser un instrumento capaz para atraer inversiones a las compañías coloniales, también debía serlo para encauzar el ahorro que permitiera la constitución de grandes empresas y el logro del desarrollo capitalista; para la segunda, el protagonismo correspondió a la proclamación del principio de igualdad de los ciudadanos ante la ley, de manera que los privilegios del soberano habrían de devenir en normas de derecho común, y con ello se robustecería el desarrollo de la actividad empresarial ${ }^{29}$.

Esta impenetrabilidad se consideró más tarde como una muestra de la deformación del concepto de persona jurídica y un presupuesto fundamental de la crisis que este

sucedió en Francia y otros países europeos. En España, en 1624 se creó la Compañía del Almirantazgo y en 1628 la Compañía de la India Oriental. Véase en extenso: Calvo Vidal, I., La persona jurídica societaria, Consejo General del Notariado, Madrid, 2011, pp. 55-57.

${ }^{25}$ El privilegio de la limitación de responsabilidad suponía en sí mismo una ventaja exclusiva o especial respecto del régimen de ordinaria aplicación. Cada compañía se constituía por medio de una concesión soberana que era fuente del privilegio específico de responsabilidad limitada, además de dividir el capital social en acciones. Galgano, F., Las instituciones de la economía capitalista. Sociedad anónima, Estado y clases sociales (traducción de Manuel Broseta Pont y Carmen Alborch Bataller), Fernando Torres - Editor, SA., Valencia, 1980, p. 92.

${ }^{26}$ De gran relevancia explicativa: De Castro y Bravo, F., La persona jurídica, Ed. Civitas, Madrid, 1981, pp. 21 y 212; Capilla Roncero, F., La persona jurídica: funciones y disfunciones, Ed. Tecnos, Madrid, 1984.

${ }^{27}$ La SA surgió en la práctica como respuesta a las exigencias de un marcado momento histórico, ya entrado el siglo XIX se abordó la cuestión de su naturaleza jurídica y su calificación jurídica como persona jurídica de tipo asociativo. Acerca de la evolución histórica de esta sociedad y los requisitos que han primado en su constitución, véase: Calvo Vidal, ob. cit., pp. 57-88.

${ }^{28}$ Para Santiago Hierro el pretendido carácter público de las compañías de comercio ha sido un mito incorrecto en la historia de la sociedad anónima. Hierro Anibarro, S., El origen de la sociedad anónima en España, Ed. Tecnos, Madrid, 1998, pp. 234-238.

${ }^{29}$ Véase Galgano, ob. cit., pp. 95-96. 
concepto sufrió ${ }^{30}$. Desde esta perspectiva, fue la creación de las sociedades anónimas un punto de inflexión frente a las ideas conservadoras que impregnaban el Derecho de sociedades hasta ese momento ${ }^{31}$. A partir de ella, la noción de persona jurídica dio un giró relevante y trascendente, pues se comenzó a utilizar para fines distintos a los que justificaron su creación, de manera tal que se incrementaron las posibilidades de abuso y se polarizó la discusión sobre la importancia del sustrato personal de las sociedades y su carácter formal ${ }^{32}$. Derivado de ello, la revisión del concepto de persona jurídica cobró una notoria relevancia a principios de siglo ${ }^{33}$, mas, tal avance no fue sostenido ni consistente ${ }^{34}$; una de las razones de ello parece encontrarse en la marcada repercusión que la doctrina jurisprudencial creada en el sistema del Common Law (Disregard of the legal entity) adquirió con el paso del tiempo, pues con ello la discusión comenzó a centrarse más en los fines de la persona jurídica (equidad y posibles abusos) que en su reconstrucción conceptual ${ }^{35}$. En este contexto, la importancia de revisar y replantear hoy la noción de persona jurídica parece inevitable, no solo por una cuestión dogmática sino también práctica, pues la determinación de sus presupuestos y efectos son cruciales en su desenvolvimiento y debida comprensión. Con todo, tal definición no parece fácil de establecer si se afronta el problema que en la mayoría de los ordenamientos este vocablo presenta contornos y presupuestos variables, y se utiliza también con relación a figuras unipersonales no siempre consideradas societarias ${ }^{36}$.

${ }^{30}$ Boldó Roda, ob. cit., p. 31.

${ }^{31}$ De Castro crítica esta inclusión esgrimiendo que: "La persona jurídica abrupte repentinamente, sin antecedentes ni justificación jurídica. Los mercantilistas se han esforzado en encontrarle una genealogía y la derivan de las sociedades nacidas en distintos países por concesión real; pero se descuida marcar su esencial diferencia con estas, caracterizadas por su naturaleza de societas publicae manifestada en todos sus caracteres: control directo del soberano en su nacimiento y administración, independencia de los gestores respecto de los socios, facultad discrecional de retirar la concesión, atribución de poderes propios de la soberanía; había pues que considerarlas”. De Castro y Bravo, ob. cit., p. 25.

32 Un caso paradigmático fue Salomón v. Salomón, que representa un claro caso en que una resolución basada en el formalismo jurídico, puede dar lugar a un resultado injusto. Acerca de esta materia puede consultarse: Boldó Roda, ob. cit., p. 42.

${ }^{33}$ Una tendencia que comenzó a inicios del siglo XX dice relación con la negación de la personalidad jurídica. Esta teoría gozó de gran aceptación entre los autores franceses como Planiol, Berthelemy, Hermard, David, entre otros. Para ellos la idea de persona jurídica no es más que una concepción superficial y falsa que encubre una antigua forma de propiedad (la colectiva), en que a diferencia de la propiedad indivisa, no hay partes individuales, sino una afectación de toda la cosa a la utilidad general. Véase: Capilla Roncero, ob. cit., pp. 72-73.

${ }^{34}$ Los precursores de esta tendencia fueron Haussmann y Mossa. Véase: De los Mozos, ob. cit., pp. 247-249.

${ }^{35}$ La divulgación de esta doctrina fue realizada principalmente por Serick, por medio de su obra Rechtform und Realitat juristischen Personen que pronto alcanzó un amplio eco en toda la doctrina europea. En Italia contribuyó Ascarelli. En España fue De Cossío, De Castro y Puig Bruteau, los que pusieron acento en la “doctrina del levantamiento del velo”. Véase: Boldó Roda, ob. cit., pp. 44-45.

${ }^{36}$ La cuestión se centra en discernir aspectos filosóficos, realistas y nominales ligados a esta noción que derivan de diversas concepciones que se pueden formular al respecto. Véase: Boldó Roda, ob. cit., p. 52. 


\section{Concerniente a la relatividad del concepto de personalidad jurídica}

Como adelantamos, un problema relevante que debe enfrentar la noción de personalidad jurídica es el hecho que no posee criterios unívocos en su concesión. Así, en la mayoría de las legislaciones se confiere la personalidad jurídica a las sociedades frente a requisitos de constitución diferenciados; o se reconoce personalidad solo a ciertos tipos societarios; o si bien se reconoce respecto de toda clase de sociedades, no en todas ellas tiene el mismo alcance ${ }^{37}$. Desde este punto de vista podríamos hablar de una relatividad de este concepto, no solo por los cambios experimentados en el transcurso del tiempo, sino porque su significado aún es variable y equívoco si lo observamos desde una perspectiva general ${ }^{38}$.

Un ejemplo que grafica con claridad lo anterior liga con reconocer que no todas las sociedades gozan de personalidad jurídica, idea que tiene sus fuentes en el derecho alemán ${ }^{39}$ y el Derecho italiano $(1942)^{40}$. El mayor acento de esta distinción es posible percibirlo respecto de las sociedades civiles, pues normalmente han existido discrepancias sobre si estas tienen personalidad jurídica ${ }^{41}$. A modo de ejemplo, en España el Código Civil preceptúa en su artículo 1669 que no tendrán personalidad jurídica las sociedades cuyos pactos se mantengan secretos entre los socios, y en que cada uno de estos contrate en su propio nombre con los terceros ${ }^{42}$. En tal contexto, surgen inquietudes y desacuerdos sobre si las sociedades civiles cuentan con dicha personalidad ${ }^{43}$, así, hay quienes apuntan que aquella debe inscribirse en el Registro mercantil u otro ad hoc para que la adquiera, o es necesaria su publicidad en el mercado; mientras que otros plantean que la dicha sociedad goza de la misma por el hecho de ser tal ${ }^{44}$. En Francia, por su parte, solo se reconoció expresamente personalidad

${ }^{37}$ Véase: Sánchez Calero, ob. cit, p. 239.
${ }^{38}$ Véase: Aguirre, ob. cit.
${ }^{39}$ Giuffrè Editore, 2007, p. 34, en Aguirre, ob. cit., p. 4.
${ }^{40}$ Schluter, Wilfre, "El derecho de sociedades en la República Federal de Alemania (1ra. parte)", en Revista del Derecho Comercial y de las Obligaciones, 1991, pp. 277-286.

${ }^{41}$ La tesis mayoritaria consideró que las sociedades comerciales tenían personalidad jurídica, a diferencia de las sociedades civiles. Autores como Boistel, Aubry y Rau negaban que las sociedades civiles constituyeran personas morales; mientras que para Lyon-Caen y Renault esta concesión derivaba de la ley y en opinión de ambos, la idea de personalidad estaba hecha solo para las sociedades comerciales. Acerca de esta materia, véase: Calvo Vidal, ob. cit., pp. 90-95.

42 Esto es bastante novedoso como tal, pues contradice no solo la tradición jurídica en este aspecto, sino la propia regulación legal de los códigos civiles que se van publicando (el francés en 1804, el italiano en 1865 , el portugués en 1866 y el alemán en 1896, por citar los más importantes ejemplos). Véase: Quesada Sánchez, A., Las sociedades civiles sin personalidad jurídica en el ordenamiento español, Ruiz-Rico Ruiz, J., (Director), Tesis doctoral, Universidad de Málaga, 2003, p. 3.

${ }^{43}$ La Resolución de la Dirección General de los Registros y del Notariado de 31 de marzo de 1997 concluye que las sociedades civiles carecen de personalidad jurídica, inspirándose en las ideas de De Castro. Pantaleón Prieto, A., "La personalidad jurídica de las sociedades civiles: contra la resolución de la DGRN de 31 de marzo de 1997”, en La Ley, Revista Jurídica española de doctrina, jurisprudencia y bibliografía, $\mathrm{N}^{\circ} 4$, Madrid, 1997 , p. 1380.

${ }^{44}$ No obstante, este criterio ha sido cuestionado por la jurisprudencia española, el caso más reciente corresponde al TSJ de Extremadura, quien en sentencia de 13 de diciembre de 2012 ha vuelto a optar por 
jurídica a la sociedad civil con la reforma del artículo 1842 del Code (1978), cuyo artículo $5^{\circ}$ del Codes des Sociétés, preceptúa: Les sociétés commerciales juissent de la personnalité morale à dater de leur immatriculation au registre du commerce et des sociétés (...), de manera que hoy resulta pacífico admitir que la atribución de personalidad jurídica se obtiene a partir de la inscripción. En Portugal, en el texto de 1867, no se reconoce expresamente personalidad jurídica a la sociedad civil, también por causa de la influencia francesa al respecto. La regulación de la sociedad civil se encuentra en el capítulo $2^{\circ}$ (Do contrato de sociedade) del título $2^{\circ}$ (Dos contratos em particular) del libro II (Dos direitos que se adquirem por ipso e contade propiae de outrem conjunctamente), artículos 1240 a 1280, y ninguno de ellos alude expresamente a la concesión de personalidad jurídica. En Italia no se personificó ni a la società civile en $1865^{45}$, ni en 1942. Uno de los artículos del Codice Civile en los que se fundamenta normativamente la división entre sociedades con y sin personalidad jurídica, es el artículo 2498 que regula la transformación de una sociedad de personas en una de capitales como transformación en sociedad con personalidad jurídica ${ }^{46}$. En Alemania, a la sociedad civil (regulada en los parágrafos 705 a 740 del BGB.60) tampoco se le reconoció expresamente personalidad jurídica, pese a que gozase de patrimonio diferenciado. Pese a todo, la sentencia del Tribunal Federal alemán II ZR 331/00, de 29 de enero de 2001, ha provocado un importante cambio al enfocar la cuestión, y ahora se duda menos sobre esa personificación.

En Latinoamérica se reconoce normalmente la personalidad jurídica a todos los tipos sociales, la disquisición reside más bien en el momento de esta concesión, esto es, desde la constitución o inscripción en el respectivo registro. A modo de ejemplo, en el derecho Argentino, el artículo. $2^{\circ}$ de la Ley 19.950, sobre sociedades comerciales señala que la sociedad es un sujeto de derecho con el alcance fijado en esta ley. De las Sociedades Civiles se encarga el artículo $33^{\circ}$ del Código Civil, que dispone: Las Personas jurídicas pueden ser de carácter público o privado. (...) Tienen carácter privado: (...) 2. Las sociedades civiles y comerciales o entidades que conforme a la ley tengan capacidad para adquirir derechos y contraer obligaciones, aunque no requieran autorización expresa del Estado para funcionar ${ }^{47}$. Se acepta expresamente la personalidad jurídica de las sociedades, sin importar el tipo

\footnotetext{
reconocer la personalidad jurídica de una sociedad civil. Véase: Quesada Sánchez, A., "La personificación de las sociedades civiles. Análisis histórico-jurídico del artículo 1669 del 'Código Civil' español”, en Revista de Derecho de la Pontificia Universidad Católica de Valparaíso, Vol. 32, Valparaíso, Chile, 2009, pp. 145-149.

${ }^{45}$ La società civile se regula en el título 10': Del contratto di società, del libro III: Dei modi di acquistare e di trasmettere la propietà e gli altri diritti sulle cose, y que ubica al contrato de sociedad, como contrato que es, junto al resto de contratos, como la compraventa, la permuta, el alquiler, el mandato o la transacción, artículos 1697 a 1736. Durante la elaboración del texto se rechazó expresamente en la Comisión de Coordinación de la Cámara de Diputados la concesión a la società civile de personalidad jurídica.

${ }^{46}$ En el 2004 se ha reformado el articulado pertinente a la transformación de sociedades de personas en sociedades de capital. Sobre esta materia, véase: Aguirre, ob. cit., p. 16.

47 Zárate, H., "Personalidad jurídica y su desestimación”, en Facultad de derecho y ciencias sociales y políticas - UNNE, Argentina, p. 2.
} 
o su regularidad estructural ${ }^{48}$. La personalidad nace conjuntamente con el acto de constitución, de manera que la sociedad existe y tiene personalidad desde el acuerdo de voluntades, con prescindencia de cualquier formalidad y de la concesión de limitación de responsabilidad de los socios ${ }^{49}$, donde sí encontramos diferencias. En Brasil, si bien se reconoce la personalidad jurídica de todas las sociedades, esta solo de obtiene una vez que la sociedad es inscrita en el respectivo registro, así el artículo 985 del Código Civil señala que la sociedad adquiere personalidad jurídica con la inscripción, en el registro propio y en la forma de la ley, de sus actos constitutivos (Arts. 45 y 1.150). En México, el artículo 25 del Código Civil señala que son personas morales $\mathrm{N}^{\circ}$ 3: Las sociedades civiles y mercantiles. En Perú, el artículo 6 de la Ley general de sociedades dispone que la sociedad adquiere personalidad jurídica desde su inscripción en el Registro y la mantiene hasta que se inscribe su extinción.

En el Derecho chileno no toda asociación goza de personalidad jurídica (Art. 19 $\mathrm{N}^{\mathrm{o}} 15$ de la $\left.\mathrm{CP}\right)^{50}$, pero sí toda sociedad, sea esta civil o comercial. En efecto, de acuerdo con el inc. $2^{\circ}$ del artículo 2053 del CC, todas las sociedades forman una persona jurídica distinta de los miembros que la componen, la personalidad jurídica de la sociedad civil, esencialmente personalista, se produce ope legis por el simple hecho de formarse, con la excepción de la sociedad de responsabilidad limitada que debe cumplir ciertas formalidades legales (Art. $2^{\circ}$ Ley 3.918); las sociedades comerciales, en cambio, deben cumplir los requisitos que para cada caso se establecen, todos diferentes entre sí ${ }^{51}$. Tal personalidad durará de manera general mientras la sociedad tenga existencia legal, prolongándose hasta su liquidación total ${ }^{52}$. Esta realidad nos llama a reflexionar referente a la necesidad de unificar los criterios que ligan con la constitución societaria ${ }^{53}$, lo que de paso se vincula con el análisis de aquellas asociaciones que por no gozar de personalidad jurídica son excluidas de la noción societaria ${ }^{54}$. En otras palabras, qué hace que una sociedad sea tal y qué elementos son esenciales a ella.

${ }^{48}$ Molina Sandoval, C., “Apostillas sobre la personalidad jurídica societaria en el derecho argentino”, en Revista e-mercatoria, vol. 3, N 1,2004 , p. 2

${ }^{49}$ Hugo Richard, ob. cit.

50 A modo de ejemplo, la "Asociación o cuentas en participación” (Arts. 507 y ss. Cco.)

${ }^{51}$ Algunas sociedades mercantiles deben escriturarse públicamente e inscribir el extracto en el Registro de Comercio correspondiente, mientras que otras, además, deben publicar dicho extracto en el Diario Oficial. Finalmente, están aquellas que pueden constituirse por medio de instrumentos privados protocolizados (sociedad por acciones). Véase: Art. 2053 Código Civil; Arts. 350-354 Código de Comercio; Arts. 424 -425 Código de Comercio; Art. $2^{\circ}$ Ley 3.918; Arts. 4 y 5 de la Ley 18.046.

${ }^{52} \mathrm{La}$ excepción a este respecto reside en cierto tipo de sociedades nulas que, a pesar de ello, gozan de personalidad jurídica y se liquidan como sociedades, como el caso de aquellas entidades que no cumplen todos los requisitos constitutivos, pero que por la sola voluntad legislativa gozan de personalidad jurídica para ciertos efectos concretos. Estas sociedades nulas poseen personalidad jurídica y pueden sanearse de acuerdo con lo dispuesto en la Ley N 19.499. Véase: Art. 357 Código de Comercio y $6^{\circ}$ de la Ley de Sociedades Anónimas.

53 Acerca de este problema, véase: Oviedo Albán, J., "La personificación jurídica societaria en el Derecho colombiano", disponible en http://www.usa.edu.co/investigacion-derecho/edicion1/La-Personificaci\%C3\%B3nJur\%C3\%ADdica-Societaria-en-el-Derecho-Colombiano.txt.pdf (20.06.2014).

${ }^{54}$ Sobre el tema, puede consultarse Calvo Vidal, ob. cit., pp. 60-65. 


\section{RELATIVO A LA EXPANSIÓN DE LA LIMITACIÓN DE LA RESPONSABILIDAD EN LAS SOCIEDADES Y OTRAS PERSONAS JURÍDICAS}

\section{Revisión del desarrollo de este privilegio}

Las compañías precodificadas se distinguían de la actual sociedad anónima porque su fundación quedaba sujeta a un acto de la autoridad pública que otorgaba, además del privilegio de la fundación, un monopolio de naturaleza comercial y una limitación de responsabilidad de los socios. La existencia de estos privilegios apartó a estas sociedades anónimas del resto de las sociedades mercantiles ${ }^{55}$. Con posterioridad a ello, la limitación de responsabilidad limitada pronto comenzó a expandirse debido a sus ventajas, primero fue a la sociedad de responsabilidad limitada en Alemania, cuyo origen se encuentra en la innovación técnica que esta legislación dio como respuesta a la necesidad de crear una compañía distinta de las tradicionales sin el riesgo de la responsabilidad personal e ilimitada de los socios en la colectiva y sin el mecanismo de funcionamiento poco ágil y costoso de la sociedad anónima, fue así como el 20 de abril de 1892 se promulgó en Alemania la Gesellschaft mit beschankter Haftung o ley de sociedades de responsabilidad limitada, modificada con motivo de la expedición del Código de Comercio de 1897 y posteriormente refundida en un ordenamiento único que se publicó el 20 de mayo de $1898^{56}$. Otros países siguieron este ejemplo, Portugal lo hizo en 1901; Polonia en 1919 y 1923; Checoslovaquia en 1920; Bulgaria en 1924; Bélgica de 1935; Francia en 1925; Suiza en 1937; Italia en 1942; y España en 1953 (modificada en 1995). Por otra parte, en Reino Unido desarrolló una práctica amparada por los Tribunales, que permitía la creación de Private companies como sociedades anónimas privadas, cuya característica fundamental era la limitación de la responsabilidad del socio. La Company Act de 1907 reconoció este nuevo tipo social con tres características fundamentales: la limitación a cincuenta del número de socios; la restricción de la transmisibilidad de las participaciones y la prohibición de invitar al público a suscribir participaciones u obligaciones de la sociedad.

${ }^{55}$ Esta sociedad nació durante la era mercantilista como respuesta jurídica a la necesidad económica de una nueva institución que sirviera para la explotación comercial de las masas de capital que habían llegado a Europa a raíz de los descubrimientos geográficos, de manera que el origen de esta sociedad se encuentra en la abundancia de capital en la economía europea del siglo XVI, producto de la apertura de nuevas rutas comerciales, lo que permitió la transformación de varias instituciones mercantiles medievales que se adaptaron a las necesidades de la Edad Moderna mediante un proceso de evolución complejo. Hierro Anibarro, ob. cit., pp. 30-45; Galgano, ob. cit., pp. 70-77.

${ }^{56}$ Es relevante destacar que antes de la promulgación de dicha ley se enfrentaron dos tendencias opuestas: una de ellas pretendía que la sociedad de responsabilidad limitada fuera básicamente una sociedad colectiva a la que se incorporaba la falta de responsabilidad de los socios por las deudas sociales, y la otra postulaba la configuración del nuevo tipo social como una sociedad anónima más simple y que debía incorporar elementos personalistas, en especial la supresión de la libre transmisibilidad de las participaciones. A base de ello, el cuerpo legal finalmente decidió configurar a esta sociedad como un híbrido entre ambas, aunque tal vez con una mayor inclinación hacia esta última. Bercovitz Rodríguez-Cano, A., La sociedad de responsabilidad limitada, Ed. Thomson Aranzadi, Navarra, 2006, pp. 45-57. 
En América Latina se reguló primero en Brasil, en 1919. En Chile, el proyecto de ley acerca de sociedad de responsabilidad limitada fue presentado al Senado por Luis Claro Solar el 7 de noviembre de 1921, aprobado por la Cámara de Diputados el 23 de febrero de 1923 y promulgado el 7 de marzo del mismo año. Una diferencia relevante que se advierte de este tipo societario reside en su configuración, pues en la mayoría de las legislaciones la sociedad de responsabilidad limitada es cercana a la sociedad de capitales o acciones, mientras que en nuestro país esta sociedad fue entendida como una sociedad de personas, a partir de lo preceptuado en el artívulo $4^{\circ}$ de la Ley $\mathrm{N}^{\circ} 3.918$, que hace aplicables a su regulación de manera supletoria a la voluntad de las partes, las normas sobre sociedades colectivas ${ }^{57}$.

Siguiendo estos derroteros, con posterioridad se comienza a discutir la posibilidad de extrapolar este beneficio de limitación de responsabilidad a la sociedad unipersonal $^{58}$, con el objeto de beneficiar al empresario individual en el ejercicio de su actividad. Esto generó una acusada resistencia en sus inicios, esgrimiendo que el contrato social, tanto en su aspecto institucional como obligacional, se erige sobre un sustrato subjetivo plural marcado por la presencia de fines o intereses que exceden del ámbito meramente individual. Bajo estas premisas, la sociedad unipersonal aparecía como una clara contraditio in terminis, en tanto que, el término de sociedad implicaba agrupación. A pesar de ello, con el paso del tiempo tal ideal se asentó en las distintas legislaciones sobre la base que es el ordenamiento el que posibilita la existencia de la persona jurídica y delimita sus contornos, por lo tanto, nada impide a la voluntad legislatoris servirse de aquella para limitar el ámbito de la responsabilidad patrimonial del empresario individual ${ }^{59}$.

${ }^{57}$ Davis, A., Sociedades civiles y comerciales, Gibbs, C., Editor, Santiago, 1963, pp. 322-323.

58 Varios han sido los autores nacionales y extranjeros que se han manifestado a favor o en contra de atender dicha demanda. En 1873 se publicó un estudio de Jessel a favor de la empresa individual de responsabilidad limitada, en él manifestó que no comprendía por qué la responsabilidad limitada era un privilegio factible mediante la constitución de una sociedad de tipo adecuado y no podía obtenerse por el individuo que desea limitar los riesgos mediante una declaración fehaciente en dicho sentido y proporcionando garantía hacia los terceros. En 1890 el suizo Speizer se plantea si el comerciante individual no puede adoptar el sistema del patrimonio autónomo para limitar su responsabilidad. En 1892 se celebró una conferencia en Suiza y en ella Wieland se declaró partidario de limitar la responsabilidad. En 1893 la Asociación suiza del Comercio y de la Industria propone la revisión del Código de las obligaciones para introducir dichas limitación de la responsabilidad. En 1897 Inglaterra, en la sentencia Salomón, admitió la validez de la sociedad unipersonal de hecho. En 1910 Pisko estudió este tema y realizó un proyecto de ley que más tarde inspiró la regulación en el Principado de Liechtenstein. Carry, en 1928 pronunció en Ginebra una conferencia sobre La responsabilité limitée du commercant individuel. En 1930 Roig Bergara fue el primer autor que en España investigó sobre la empresa individual de responsabilidad limitada. Vivante abordó este tema en 1934 y 1938, Ischer publicó en Lausana su obra Vers la responsabilité limitée du mercant individuel. En 1964 Rotondi y en 1967 Grisoli, siguieron la tesis de Vivante. Véase en detalle: Boquera Matarredona, J., "La sociedad unipersonal de responsabilidad limitada", en Estudios de Derecho mercantil, Ed. Civitas, Madrid, 1996, pp. 23-25.

${ }^{59}$ Calvo Vidal, ob. cit., pp. 319-321. 
La primera legislación tuvo ocasión con una importante modificación al Código Civil del Principado de Liechstenstein en materia de sociedades y personas jurídicas, verificada mediante ley de 20 de enero de 1926 (artículos 834 al 896). Con posterioridad a ello se comenzó a legislar la posibilidad de acoger la sociedad unipersonal sobrevenida, y luego la originaria. En este camino fueron también los países de origen germano los primeros en reconocer ampliamente la alternativa fundacional unisubjetiva de la sociedad de responsabilidad limitada, luego lo harán otros países europeos. En efecto, lo hizo Dinamarca en primer término ${ }^{60}$, luego Alemania ${ }^{61}$; Bélgica ${ }^{62}$; Holanda ${ }^{63}$; Portugal $^{64}$; Italia ${ }^{65}$. En Francia los orígenes mediatos de la sociedad unipersonal inicial se encuentran en el proyecto de Empresa Personal de Responsabilidad Limitada presentado en 1978 que no prosperó debido a la concepción contractual predominante, pero que finalmente se recogió en la Ley $\mathrm{N}^{\circ}$ 85-697, de 11 de julio de $1985^{66}$. En España, el artículo 12 de la actual Ley de sociedades de capital (RDL 1/2010) acoge expresamente la figura unipersonal, tanto en su forma originaria como sobrevenida ${ }^{67}$. En Inglaterra, por su parte, la Companies Regulations Act de 15 de julio de 1992, por transposición de la Directiva 89/667/CEE, autoriza a constituir y mantener una sociedad con un solo socio en las denominadas Limited Private Companies, manteniéndose en cambio el requisito de la pluralidad fundacional en las Public Companies y en las Unlimited Private Companies ${ }^{68}$. Finalmente, cabe mencionar la $12^{a}$ Directiva 89/667/CEE del Consejo en materia de sociedades, de 1989, que otorga un punto de apoyo crucial para la admisión de esta

${ }^{60}$ Ley danesa sobre sociedades de responsabilidad limitada, No 371 de 13 de junio de 1973.

${ }^{61}$ La ley alemana de 4 de abril de 1980 modificó sustancialmente la $G m b H G$ de 1882, permitiendo la fundación de una sociedad de responsabilidad limitada por un solo socio, persona natural o jurídica

${ }^{62}$ Ley de 5 de diciembre de 1984 que admite la sociedad anónima unipersonal y la ley de 14 de julio de 1987 admite las sociedades unipersonales con responsabilidad limitada.

${ }^{63}$ Ley de 16 de mayo de 1986, modificatoria del Código Civil, permitió la fundación por un solo socio - persona natural o jurídica- de una sociedad de responsabilidad limitada y también -por primera vez en Europa- de una sociedad por acciones (artículos 64 y 175 del C.C. holandés).

${ }^{64}$ El Decreto-ley $\mathrm{N}^{\circ} 248$ de 25 de agosto de 1986 introduce la empresa individual de responsabilidad limitada.

${ }^{65}$ Con fecha 19 de febrero de 1992 se aprobó la ley 142 referente a Disposizioni per l1adempimento di obblighi derivati dall'appartenza dell'Italia alle Comunitá europee, donde se delegaba al gobierno el que emanase, en el término de un año desde la fecha de entrada en vigor de la presente ley, los decretos legislativos que contengan las normas necesarias para dar actuación a las directivas de la Comunidad Europea. El artículo 17 del citado precepto establece los criterios de delegación para las sociedades de capitales unipersonales.

${ }^{66}$ La misma ley modificó la definición de sociedad que se contenía en el artículo 1832 del Código Civil francés, agregándole el siguiente inciso segundo: En los casos previstos por la ley, puede ser instituida por el acto de voluntad de una sola persona.

${ }^{67}$ Antes de ello, el legislador español había incorporado ya la sociedad de responsabilidad limitada y la sociedad anónima unipersonal, originaria o sobrevenida, optando de esa forma por esta última figura antes que por la EIRL (Arts. $1^{\circ}$ y 125 de la Ley de Sociedades de Responsabilidad Limitada)

${ }^{68}$ Que modifica la Companies Act de 1985 y la Insolvency Act de 1986. 


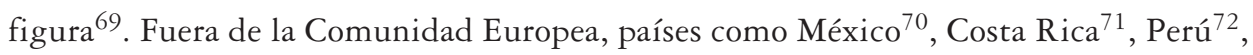
San Salvador, Panamá, Colombia ${ }^{73}$, algunos estados de Estados Unidos de América, entre otros, tienen leyes que admiten el ejercicio individual del comercio con el beneficio de la responsabilidad limitada. En Chile, si bien en un inicio no se reconoce a la figura de la sociedad unipersonal por la idea contractual predominante, finalmente se acoge tal posibilidad a partir de la Ley 19.857 de 2003, que autoriza el establecimiento de las Empresas Individuales de Responsabilidad Limitada (EIRL $)^{74}$.

Con posterioridad a ello, se han creado otras figuras societarias que contemplan este privilegio, la más relevante es seguramente la Sociedad por acciones simplificada (SAS) francesa de 1994. En Chile se sigue este ejemplo de cerca, configurando la sociedad por acciones $(\mathrm{SpA})^{75}$ que además de permitir la constitución unipersonal, otorga el privilegio de la responsabilidad limitada, sumándose, de esta forma, a la existencia predominante en la materia. En este estado de cosas, solo las sociedades colectivas (civil y comercial) y en comanditas (respecto de los socios gestores) no disponen de este manto protector, lo que se explica por la época de su creación, muy anterior al nacimiento del privilegio de la responsabilidad limitada, y cuando se han efectuado reformas en la materia, el legislador se ha ocupado de la creación de nuevos tipos societarios (todos con el privilegio) y no de revisar las antiguas configuraciones.

Vemos entonces que la tendencia predominante en el proceso de modernización del Derecho societario ha sido la extensión de la limitación de responsabilidad limitada de manera uniforme a los tipos societarios, los que debido a este manto protector son las sociedades mayoritariamente elegidas por las partes al momento de revestir su empresa de personalidad jurídica. A modo de ejemplo, presentamos un gráfico que recoge los datos estadísticos acerca de las sociedades constituidas en los últimos diez años en Chile. Se observa que la elección se inclina a los tipos societarios que gozan de este privilegio y a la EIRL que, como señalamos, también está protegida por este manto legal.

${ }^{69}$ Referente a esta materia, véase: Boquera, ob. cit., pp. 44-52; Jequier, E., "Unipersonalidad y sociedad con un solo socio; alcances de su reconocimiento en la estructura dogmática del derecho chileno", en Revista Ius et Praxis, Año 17, N² 2, 2011, pp. 189-230; Calvo Vidal, ob. cit., pp. 319-324.

70 Artículo 57 de la ley mexicana sobre sociedades comerciales de 1934 admite la sociedad de responsabilidad limitada individual.

${ }^{71}$ Artículos 9 a 16 del Código de Comercio regulan la empresa individual de responsabilidad limitada.

72 Decreto-ley de 1976 regula la empresa individual de responsabilidad limitada.

${ }^{73}$ Ley 1258 de 2008 (SAS). Sobre esta norma, véase: Reyes Villamizar, F., SAS. La sociedad por acciones simplificada, Ed. Legis, 2010 ( $2^{\circ}$ ed.).

${ }^{74}$ Sobre esta figura y algunos de sus problemas, puede consultarse: Corral Talciani, H., y Díaz Villalobos, J. (Editores), Las empresas individuales de responsabilidad limitada, Cuadernos de extensión jurídica, Universidad de los Andes, 2004.

75 Arts. 424 a 446 Cco., creada a partir de la Ley 20.190 publicada en el Diario Oficial, el 5 de junio de 2007. 
* Cuadro resumen de sociedades constituidas en Chile entre los años 2003-2013

\begin{tabular}{|c|c|c|c|c|c|c|c|c|}
\hline Año & Total SA & SRL & EIRL & $\begin{array}{l}\text { Soc. en } \\
\text { comandita }\end{array}$ & $\begin{array}{c}\text { Soc. } \\
\text { colectiva }\end{array}$ & $\mathrm{SpA}$ & $\begin{array}{c}\text { Soc. en } \\
\text { comandita } \\
\text { por acción }\end{array}$ & Total \\
\hline 2003 & $\begin{array}{c}3.883 \\
(16,21 \%)\end{array}$ & $\begin{array}{c}18.040 \\
(75,32 \%)\end{array}$ & $\begin{array}{c}2.026 \\
(8,45 \%)\end{array}$ & 0 & $\begin{array}{c}1 \\
(0,02 \%)\end{array}$ & 0 & 0 & 23.950 \\
\hline 2004 & $\begin{array}{c}4.347 \\
(16,89 \%)\end{array}$ & $\begin{array}{c}18.160 \\
(70,55 \%)\end{array}$ & $\begin{array}{c}3.233 \\
(12,56 \%)\end{array}$ & 0 & 0 & 0 & 0 & 25.740 \\
\hline 2005 & $\begin{array}{c}4.658 \\
(16,30 \%)\end{array}$ & $\begin{array}{c}19.769 \\
(69,17 \%)\end{array}$ & $\begin{array}{c}4.152 \\
(14,53 \%)\end{array}$ & 0 & 0 & 0 & 0 & 28.579 \\
\hline 2006 & $\begin{array}{c}4.409 \\
(26,86 \%)\end{array}$ & $\begin{array}{c}8.350 \\
(50,88 \%)\end{array}$ & $\begin{array}{c}3.650 \\
(22,25 \%)\end{array}$ & 0 & $\begin{array}{c}2 \\
(0,01 \%)\end{array}$ & 0 & 0 & 16.411 \\
\hline 2007 & $\begin{array}{c}4.602 \\
(18,89 \%)\end{array}$ & $\begin{array}{c}14.490 \\
(59,47 \%)\end{array}$ & $\begin{array}{c}5.155 \\
(21,16 \%)\end{array}$ & 0 & 0 & $\begin{array}{c}115 \\
(0,48 \%)\end{array}$ & 0 & 24.362 \\
\hline 2008 & $\begin{array}{c}4.175 \\
(26,16 \%)\end{array}$ & $\begin{array}{c}7.248 \\
(45,43 \%)\end{array}$ & $\begin{array}{c}3.876 \\
(24,29 \%)\end{array}$ & 0 & 0 & $\begin{array}{c}653 \\
(4,09 \%)\end{array}$ & $\begin{array}{c}1 \\
(0,01 \%)\end{array}$ & 15.955 \\
\hline 2009 & $\begin{array}{c}4.416 \\
(25,52 \%)\end{array}$ & $\begin{array}{c}7.652 \\
(44,22 \%)\end{array}$ & $\begin{array}{c}4.201 \\
(24,27 \%)\end{array}$ & 0 & $\begin{array}{c}1 \\
(0,005 \%)\end{array}$ & $\begin{array}{c}1.033 \\
(5,96 \%)\end{array}$ & 0 & 17.307 \\
\hline 2010 & $\begin{array}{c}3.841 \\
(8,73 \%)\end{array}$ & $\begin{array}{c}27.024 \\
(61,41 \%)\end{array}$ & $\begin{array}{c}10.356 \\
(23,53 \%)\end{array}$ & 0 & 0 & $\begin{array}{c}2.670 \\
(6,06 \%)\end{array}$ & $\begin{array}{c}3 \\
(0,01 \%)\end{array}$ & 44.007 \\
\hline 2011 & $\begin{array}{c}3.899 \\
(6,67 \%)\end{array}$ & $\begin{array}{c}34.404 \\
(58,88 \%)\end{array}$ & $\begin{array}{c}14.632 \\
(25,04 \%)\end{array}$ & 0 & $\begin{array}{c}1 \\
(0,01 \%)\end{array}$ & $\begin{array}{c}5.406 \\
(9,25 \%)\end{array}$ & 0 & 58.432 \\
\hline 2012 & $\begin{array}{c}3.347 \\
(5,03 \%)\end{array}$ & $\begin{array}{c}37.641 \\
(55,07 \%)\end{array}$ & $\begin{array}{c}17.618 \\
(25,82 \%)\end{array}$ & 0 & 1 & $\begin{array}{c}9.587 \\
(14,03 \%)\end{array}$ & 0 & 68.329 \\
\hline 2013 & $\begin{array}{c}2.289 \\
(4,16 \%)\end{array}$ & $\begin{array}{c}27.234 \\
(49,53 \%)\end{array}$ & $\begin{array}{c}14.182 \\
(25,82 \%)\end{array}$ & 0 & 0 & $\begin{array}{c}11.259 \\
(20,47 \%)\end{array}$ & 0 & 54.980 \\
\hline
\end{tabular}

Llegados a este punto, la pregunta que surge naturalmente es por qué no extender dicho privilegio a las sociedades que actualmente no cuentan con aquel, pues, tal como están configuradas, carecen hoy de una utilización sostenida. En otras palabras, ¿por qué extender solo a algunas sociedades este privilegio y no a todas?, ¿qué fundamentos podrían justificar dicha decisión?

${ }^{76}$ Catastro construido sobre la base de la información disponible en el Diario Oficial. En este punto debe tenerse presente que el Derecho societario chileno carece de un registro público unificado respecto de todos los tipos societarios, el que habría arrojado datos más certeros acerca de estos números. 


\section{Estudio de algunos antecedentes prácticos de la limitación de responsabilidad: justificación $y$ consecuencias}

La responsabilidad es la sujeción al poder del acreedor de exigir coactivamente el cumplimiento de una obligación, de manera que ello se traduce en una forma de sanción del incumplimiento del débito que es un acto antijurídico. Implica que la persona soporta las consecuencias del incumplimiento de sus obligaciones y facilita la realización del derecho de sus acreedores, en tal sentido, una norma que otorga seguridad es aquella que establece la responsabilidad patrimonial ilimitada del deudor ${ }^{77}$. Frente a ello, la limitación de la responsabilidad debe encontrar un fundamento consistente.

Indagando en relación con esta materia advertimos que el primer argumento conferido al respecto se fundó en la no intervención del que aporta capital en la gestión social, de manera que se establece una correlación entre responsabilidad y gestión ${ }^{78}$, así se da, por ejemplo, respecto de los socios comanditarios en las sociedades en comanditas; sin embargo, si bien tal silogismo fue sostenible en los inicios de la cuestión, aquel se diluyó con el paso del tiempo ${ }^{79}$. En la actualidad el hermetismo patrimonial se asocia a la inversión, lo que nos lleva a reconocer un cambio de paradigma en relación con la estructura social y la concesión de la personalidad jurídica, en cuanto se comenzó a ver a la sociedad como un mecanismo de emprendimiento al servicio de los particulares. Esto se debe a que en las economías capitalistas existen necesidades de expansión y la consecuente necesidad de controlar los riesgos que nacen de la empresa, lo que ha terminado por derribar las barreras axiológicas que podrían haber justificado, en ciertos casos, la ilimitación de la responsabilidad. Estas barreras han ido cediendo por razones prácticas y ante desarrollos dogmáticos que han hecho posible y atractiva la expansión del régimen de limitación de responsabilidad, más allá de los supuestos aceptados hace un siglo; a base de lo anterior, hoy la limitación a la cantidad invertida es una característica de gran parte de las inversiones, especialmente en el derecho de sociedades. Bajo estas circunstancias, la responsabilidad limitada se ofrece como un dogma, una construcción cuya existencia dejó de ser objeto de revisión que no solo ha sido una constante de los sistemas jurídicos modernos, sino que -como vimos más atrás- se ha expandido decididamente.

Entre las consecuencias de esta limitación podemos advertir aspectos económicos y jurídicos. En el primer caso, encontramos el traslado de los riesgos, pues el costo de la limitación de responsabilidad se traspasa de los socios a los acreedores. Por otra parte, este mecanismo disminuye la necesidad de supervisar a los agentes y proporciona

${ }^{77}$ Diez Picazo, L., Fundamentos de Derecho Civil Patrimonial, Vol. I, Ed. Tecnos, Madrid, 1986, $2^{\circ}$ ed, p. 341 .

78 Boquera, ob. cit., p. 22.

${ }^{79}$ En Chile no se establecen limitaciones al respecto, de manera que el o los socios/empresario que aporta puede administrar la sociedad/empresa. Véase Ley 3.918; Ley 19.857 (Art. 9); Arts. 424 y ss. Código de Comercio. 
incentivos a los directivos para comportarse de manera eficiente. Asimismo, el valor de las acciones se calcula en función del valor actual del flujo de rentas que genera el patrimonio de la empresa, lo que también se vincula a la fungibilidad de las acciones; como correlato de ello, la responsabilidad limitada hace posible que los precios de mercado reflejen información adicional concerniente al valor de las empresas, pues las acciones no constituyen una mercadería homogénea, ni tienen un precio único de mercado, de manera que se exige a los inversores el empleo de más recursos para analizar las expectativas de la empresa en aras de advertir si el precio es correcto. A ello se agrega que la responsabilidad limitada permite una diversificación más eficiente, pues las personas pueden reducir el riesgo por medio de una tenencia de una cartera de inversiones diversificada. Finalmente, promueve decisiones de inversión óptimas, pues los administradores maximizan el bienestar de los inversores empleando recursos en cualquier proyecto que tenga un valor actual neto positivo ${ }^{80}$.

Desde el escenario jurídico, se trata de un mecanismo en donde las pérdidas son absorbidas más que trasladadas, pues cada inversor tiene asignada una parte que debe soportar; a base de ello, y ya que se incrementa la posibilidad que no existan bienes suficientes para satisfacer las pretensiones de los acreedores, se termina por imponer un costo social mayor ${ }^{81}$, lo que nos invita a reflexionar acerca de las medidas que se pueden utilizar para la reducción de un impacto no deseable. Lo anterior va de la mano con una discusión que aún no ha tenido lugar de manera clara en nuestra legislación, y que liga con la necesidad de contar con garantías jurídicas adicionales, como ocurre con un capital mínimo para comenzar a operar (capitalización e infracapitalización) ${ }^{82}$; la exigencia de requerimientos suficientes para la disminución del capital social; la fijación de intereses; la configuración de la responsabilidad de los administradores frente a determinadas circunstancias; la operatividad y reconocimiento expreso de la doctrina del levantamiento del velo; entre otros. Las medidas expuestas se vislumbran como una tentativa de equilibrio entre los beneficios y costes que genera la responsabilidad limitada, de manera que en nuestra consideración debieran ser analizados como tales.

${ }^{80}$ Sobre este tema, Marcos, F., "La responsabilidad limitada”, en Instituto de empresa, 2002, pp. 5 y 6.

${ }^{81}$ Ibid., pp. 6-7.

82 Sobre este punto debemos recordar que la legislación chilena exige un capital mínimo en contadas ocasiones: Por ejemplo: DFL N 251 sobre Compañías de Seguros, Sociedades Anónimas y Bolsas de Comercio (Ley 18.045); Art. 24 del DL N³ 3.500 que establece el Nuevo Sistema de Pensiones y el Art. 178 del DFL N ${ }^{\circ} 1$ que fija el texto refundido, coordinado y sistematizado del DL $\mathrm{N}^{\circ} 2.673$ de 1979 y de las Leyes $\mathrm{N}^{\circ} 18.933$ y 18.469 . Otra forma de protección para los terceros es la que establece la legislación laboral (Art. 183 del CDT). Esta norma obliga a la empresa de servicios transitorios a constituir una garantía permanente a nombre de la Dirección del Trabajo, cuyo monto mínimo es de $250 \mathrm{UF}$, que debe ajustarse cada 12 meses considerando el número de trabajadores transitorios que se encuentren contratados. 


\section{Acerca de los abusos de la personalidad Jurídica y la limitación de RESPONSABILIDAD. MECANismos QUE LO REVIERTEN}

\section{Relativo a los abusos de la personalidad jurídica societaria y una aproximación a la doctrina del levantamiento del velo}

Los abusos que se producen con relación a la persona jurídica societaria tienen su punto de partida en el nacimiento de la concesión de la limitación de responsabilidad limitada ${ }^{83}$, pues con ello cambia la fundamentación teórica de la primera ${ }^{84}$. A partir de ello, se ha considerado que esta impenetrabilidad ha contribuido a la deformación del concepto de persona jurídica manifestada en su generalización mediante diversas etapas de la evolución dogmática, pues con ella se abre una zona ilimitada de toda clase de abusos ${ }^{85}$. Esto ocurre porque la personalidad jurídica, en conjunción con la limitación de responsabilidad limitada, ha hecho posible que, bajo la apariencia de un acto ajustado a derecho, se persiguieran fines ilícitos ${ }^{86}$ con consecuencias no queridas por el legislador; frente a ello emerge la doctrina del "levantamiento del velo" que pretendió romper el aludido hermetismo para hacer responsables a los socios de las obligaciones de la sociedad pese al mantenimiento de la estructura social, es decir, se le imputan las responsabilidades a los socios directamente sin que ello implique la desaparición de la persona jurídica, ni la disolución de la sociedad.

El objeto de esta doctrina es evitar soluciones contrarias al espíritu del ordenamiento jurídico, lo que se produciría si se mantuviese tajantemente la separación entre la sociedad y los socios. Sin embargo, la disección de los casos en que es posible su aplicación no es sencilla pues está en riesgo la desnaturalización de la personalidad jurídica, de manera que un punto relevante consiste en desentrañar su correcta aplicación reaccionando contra

${ }^{83}$ Véase: De Castro y Bravo, ob. cit., pp. 21 y 212.

${ }^{84}$ Sobre ello, véase: Boldó Roda, ob. cit., p. 37.

${ }^{85}$ De Castro y Bravo, ob. cit., p. 249; Serick, R., Apariencia y realidad en las sociedades mercantiles. El abuso de derecho por medio de la persona jurídica, Ed. Ariel, Barcelona, 1958, pp. 84 y ss.; Capilla Roncero, ob. cit., pp. 69 y ss.

${ }^{86}$ Referente a esta materia, puede consultarse: Boldó Roda, ob. cit.; Lyon Puelma, A., Personas jurídicas, Abuso de la Forma, Gobierno Corporativo y Responsabilidad, Derechos y Obligaciones de los Miembros, Divisiones, Fusiones, Conflictos de Interés, Control, Santiago, Ediciones Universidad Católica de Chile, 2004, pp. 62 y ss.; López Díaz, P., La doctrina del levantamiento del velo y la instrumentalización de la Personalidad Jurídica, LexisNexis, Santiago de Chile, 2003, pp. 35-68; Aguad Deik, A., "Los límites de la personalidad jurídica. La doctrina del levantamiento del velo", en Estudios sobre reformas al código civil y código de comercio. Teoría de los riesgos. Reformas al derecho internacional privado. El abuso de la personalidad jurídica. La protección de la apariencia en el derecho civil, Ed. Jurídica de Chile, Santiago de Chile, 2002, p. 293 y ss.; López Fernández, D., La empresa como unidad económica, Ed. Abeledo Perrot-LegalPublishing, Santiago de Chile, 2010, pp. 2 y ss.; Irureta Uriarte, P., "Aplicaciones de la doctrina del levantamiento del velo corporativo", en Actas de las II Jornadas de Derecho de la Empresa, Santiago, Facultad de Derecho de la Pontificia Universidad Católica de Chile, 2005, pp. 253-258; Varela Fleckenstein, A., "La doctrina del levantamiento del velo en la jurisprudencia nacional", en Vásquez, M. (Coord.), Estudios de derecho comercial, Ed. AbeledoPerrot-LegalPublishing, Santiago de Chile, 2011, pp. 83-113; Lojendio Osborne, Núñez Lozano, ob. cit., p. 18; Véase: Lara Aguayo, E., "La crisis del concepto de persona jurídica y el levantamiento del velo”, en Gaceta Jurídica, No 314, Santiago, 2007. 
la utilización de las formas legales que pretenden contrariar o burlar el orden jurídico. Frente a ello, es preciso comprender que la determinación de esos límites implica interpretar la norma de manera adecuada; por otra parte, antes de aplicar esta tesis, se debiera recurrir y descartar la aplicación de otras posibles instituciones, por ejemplo, la nulidad, la simulación, acciones revocatorias y paulianas, entre otras ${ }^{87}$, de tal manera que su utilización se entiende como subsidiaria, residual y limitada al objeto de frustrar la finalidad ilegítima perseguida en perjuicio de los acreedores ${ }^{88}$.

Desde un enfoque general pueden plantearse tres principios para levantar el velo jurídico de una sociedad: 1. Que la personalidad no puede amparar los actos ejecutados en fraude a la ley; 2. Que los derechos han de ejercitarse según las exigencias de la buena fe; y 3. Que la ley no ampara el abuso del derecho en daño ajeno o del derecho a los demás, de manera que entre seguridad y justicia debe prevalecer esta última ${ }^{89}$. Estas pueden reconducirse incluso a una sola causal: el atentado a la "buena fe", que se traduce en una burla o lesión del contrato y otros daños fraudulentos causados a terceros ${ }^{90}$. En tal sentido, el juez deberá tener en consideración que la persona jurídica constituye una ficción creada en atención al tráfico jurídico y negocial que ha de respetar el principio de buena fe y el espíritu de las disposiciones sociales de forma total. En general, esta tesis se ha aplicado de manera diferente entre los países del Common Law y los del Civil Law ${ }^{91}$.

Sobre la base de la experiencia de Derecho comparado podemos afirmar que aquella se ha orientado a desconocer o atravesar la personalidad jurídica frente a casos concretos, entre los que se encuentran: 1) Unidad de empresas: cuando por encima de la pluralidad de sociedades, existe identidad de sujetos o esferas, unidad de empresa o confusión de patrimonios. 2) Infracapitalización (nominal o material), en el caso de las sociedades que no han sido dotadas de capital adecuado a los riesgos empresariales asumidos o al establecido legalmente, lo que sugiere ignorar la personalidad jurídica de la sociedad y exigir

87 Véase: Puelma Accorsi, ob. cit., pp. 106-109.

${ }^{88} \mathrm{La}$ primera decisión judicial donde se dio aplicación a la doctrina disregard of legal entity tiene su antecedente en Estados Unidos en 1809 (fallo Bank of the United States v. Deveaux). Luego se trasladó a Europa a través de la obra de Rolf Serick, llamada "Rechstform und realität jurisdichten personen", en ella se estableció que procedía la desestimación de la personalidad jurídica cuando los socios, abusando de dicha personalidad, persiguen fines ilícitos o fraudulentos, dañando a terceros. Jaramillo Herrera, L., "Desestimación de la personalidad jurídica en el derecho societario colombiano”, en Revista CES derecho, Vol. 2, No 2, juliodiciembre 2011, pp. 127-128.

89 Sobre el tema, Sánchez Calero, F., y Sánchez-Calero Guilarte, J., Instituciones de Derecho Mercantil, Vol. I, 29a edición, Thomson-Aranzadi, Navarra, 2006, pp. 317 y ss.

${ }^{90}$ Lyon Puelma, Personas jurídicas, abuso..., ob. cit., p. 65; Aguad Deik, op. cit., p. 293.

${ }^{91}$ Los jueces norteamericanos e ingleses han desestimado la personalidad jurídica de las sociedades aplicando directamente a los socios los efectos de las normas legales que éstos habían pretendido eludir teniendo en consideración los intereses públicos generales cuando el objeto de la sociedad estaba directamente dirigido a penetrar un fraude a terceros; en el caso que la responsabilidad limitada de la corporación lesionaba la equidad; o cuando la desestimación de la personalidad jurídica de la sociedad era necesaria para evitar que se consumara una injusticia. En los países de legislación codificada, constreñidos por el respeto tradicional de los textos positivos, no se ha podido exhibir una amplitud y claridad de reglas, no obstante, como el problema es latente, en la práctica se han elaborado ciertos criterios para corregir los abusos o arbitrios venidos desde estos abusos. 
la responsabilidad personal de sus socios de control. 3) Control o dirección externa efectiva, en donde los acuerdos de la sociedad controlada debe responder la sociedad dominante, lo que supone una falta de capacidad de autodeterminación (jurídica o económica) de una sociedad que satisface en realidad los intereses de otra. Ello se da comúnmente en los grupos de sociedades y supone una situación de concentración empresarial y de subordinación entre las sociedades. 4) Fraude a la ley o de acreedores, por ejemplo, venta a bajo precio a determinadas sociedades del grupo o transfer pricing o del paquete de control de una sociedad a una sociedad instrumental para que esta lo revenda al verdadero comprador a un precio muy superior, lucrándose los vendedores como socios de la sociedad instrumental. 5) Operaciones con el socio controlador o mayoritario, que trata de la realización de operaciones constantes entre el socio controlante y la sociedad, sirviéndose de ella como un instrumento o herramienta para cumplir objetivos e intereses personales, en beneficio propio o en el de un tercero self dealing transactions. 6) Confusión de patrimonios $y$ negocios al interior de una sociedad -commingling of assets and business-, junto con la imposibilidad de diferenciar el capital social con el patrimonio personal de los socios.

\section{Aplicación del levantamiento del velo en Chile: criterios recogidos}

El Derecho chileno ${ }^{92}$ no alberga causales para la aplicación de esta sanción a diferencia de lo que ocurre en otros sistemas jurídicos ${ }^{93}$, lo que sí contiene son diferentes campos normativos que prevén la posible comisión de abusos como ocurre con las acciones de nulidad, revocatorias y de actos simulados. Otras normas se acercan a la idea de prescindir de la personalidad jurídica en ciertos casos, por ejemplo, la Ley General de Bancos al establecer varios límites en relación a las operaciones de crédito que puede otorgar un banco (Arts. $3^{\circ}, 84$ y 85); el artículo 12 letras c), d) y e) de la Ley 19.957, que regula la Empresa Individual de Responsabilidad Limitada, al recoger supuestos concretos que permiten descorrer el velo de la personalidad, debiendo el titular responder

92 Ugarte Vial, J., "Fundamentos y acciones para la aplicación del levantamiento del velo en Chile", en Revista chilena de derecho, vol. 39, N 3, 2012.

93 Así, por ejemplo, en el derecho colombiano, la Ley 190 de 1995 dicta normas tendientes a preservar la moralidad en la Administración Pública, la que establece en su artículo 44 que los jueces pueden levantar el velo corporativo de las personas jurídicas para determinar quién es el verdadero beneficiario de las actuaciones realizadas por ella. Adicionalmente, la Ley 1116 del 2006 preceptúa el Régimen de Insolvencia Empresarial, señala en el artículo 49 numeral 8, que en cuanto a la apertura del proceso de liquidación judicial, si el juez verifica que la sociedad no cumple sus deberes legales, especialmente el de llevar contabilidad, podrá ordenar la disolución y liquidación del ente y los acreedores podrán demandar subsidiariamente la responsabilidad de los administradores, socios y controlantes de la sociedad. Por su parte, en el Derecho argentino se habla de inoponibilidad de la personalidad jurídica societaria, este efecto irradia la idea de que la sociedad nace con todos sus atributos, pero en determinadas circunstancias tal diferenciación de personalidad no es oponible a terceros. En Francia se presenta en forma segmentada, para resolver casos particulares, especialmente en el campo concursal, como por ejemplo el fallo precursor dictado por la Corte de Casación francesa en 1908 "Mary Raynaud", modificando el criterio existente hasta entonces en el mundo galo. El derecho estadounidense efectuó una sistematización a nivel de diversos institutos típicos de su sistema, en especial la agency, el fraude y el estoppel. Sobre esta materia, véase: Jaramillo Herrera, ob. cit., p. 128; Zárate, ob. cit., p. 2. 
ilimitadamente en concordancia con el derecho de prenda general (Arts. 2465 y 3469 CC) ${ }^{94}$; artículos 17, 18 y 96 de la LMV relativos a los grupos de empresas, controladores y personas relacionadas; así como los artículos 86 y siguientes de la LSA, relativos a las filiales y coligadas y 94 y siguientes del mismo cuerpo legal, acerca de la división, fusión y transformación de las sociedades.

Más allá de ello, nuestros tribunales superiores de justicia se han pronunciado con referencia a esta materia en contados casos, y a pesar de la ausencia de criterios legales expresos han acogido algunas de las tesis que antes apuntamos. En efecto, esta doctrina ha tenido acogida ante la presencia de la identidad personal o patrimonial entre una sociedad y uno o más de sus socios, administradores o sociedades relacionadas; y también debido a la instrumentalización abusiva de la sociedad para la consecución de un fraude a la ley o a los derechos de terceros ${ }^{95}$. Así por ejemplo, la Corte Suprema ha esgrimido la unidad de empresas como causa de la desestimación ${ }^{96}$, el criterio del fraude a terceros ${ }^{97}$, y también el control o dirección externa ${ }^{98}$. Por su parte, en materias laborales la jurisprudencia ha sido abundante y concluyente en la configuración de la noción de "unidad económica" o bolding para extender la responsabilidad más allá del empleador formal ${ }^{99}$.

Con la intención de forjar bases jurídicas más sólidas frente a estos supuestos debieran construirse causales legales concretas para la aplicación de la desestimación de la personalidad jurídica societaria; o bien, configurar otros mecanismos que brinden este resguardo. Uno de ellos podría ser una acción especial de inoponibilidad que podría conferirse como un acto declarativo en virtud del que se pueda solicitar que se prescinda de la personalidad jurídica de una sociedad de cuya estructura se ha abusado, de modo

94 Véase: Lara Aguayo, E., "Descorriendo el velo corporativo de la empresa", en Jornadas ChilenoUruguayas de derecho comercial, Ed. Librotecnia, Santiago, 2011, pp. 53-63.

95 Ugarte Vial, ob. cit.

96 Sentencia, Corte Suprema, de 25 de marzo de 2008, caratulada Banco Scotiabank Sudamericano con Campodónico Quiroga, Oscar, Rol 6043-06, MJJ16872; Sentencia 2 junio 2009, caratulada Consorcio Allianz de Seguros Generales (actualmente A GF Allianz Compañía de Seguros Generales S. A.) con Sociedad Naviera Ultrajas Ltda. y otra, Rol No 1527-08, a base de datos de: www.Microjuris.cl, [visitado el 10/10/2012].

97 Corte Suprema, 12 de enero de 2006, Rol 2331-2006.

98 Corte de Apelaciones de Punta Arenas, de 27 de marzo de 2008, en causa Salomón Catrilef Hernández y otros con Pesca Cisne S.A.

${ }^{99}$ Ejemplos de ello los encontramos en Sentencia, Excma. Corte Suprema, se rechaza recurso de casación en el fondo, de 19 de julio de 2001, caratulada Hernán Bordagara y Vásquez y otros con Mutuos Hipotecarios Santa Fe SA y otras, Rol 1.933-01, cita CL/JUR/4097/2001; 22314, Corte Suprema, se acoge recurso de casación en el fondo, de 13 de agosto de 2003, Rol No 4.005-02, cita CL/JUR/1039/2003; 28437. Iltma. Corte de Apelaciones de Concepción, recurso de apelación se confirma la sentencia, caratulada Carlos Mellado Backarzick con Sociedad Administradora de Servicios de Vigilancia Unimarc S.A., Rol N $3.199-05$ cita: CL/ JUR/8097/2006; 35115_CA, todo a base de datos de: www.LegalPublishing.cl, [visitado el 10/10/2012]. Véase: Sentencia Excma. Corte Suprema, se acoge recurso de casación en el fondo, de 11 de noviembre de 2009, caratulada Distribuidora Magallanes Limitada contra Llegar, Andrea, Rol 6.070-09. A base de datos de: www.legalpublishing.cl, cita: CL/JUR/3286/2009; 43085. Otros fallos relevantes en la materia son los pronunciados por la Corte de Apelaciones de Talca, 29 de junio de 2010, Rol 50-2010, N ${ }^{\circ}$ ID LP 45551; Corte de Apelaciones de Talca, 27 de mayo de 2010, Rol 1869-09, revocada por la CS de 22 de julio de 2010, Rol 4192-10, ID LP 45243; Corte Suprema, 12 de agosto de 2010, Rol No 865-2009, ID LP 45513. 
que los efectos jurídicos que se ha intentado vulnerar o evadir mediante la comisión de un acto fraudulento se atribuyan directamente a quienes han cometido o permitido tal abuso, ya sea uno de los socios, un administrador con poderes para controlar de hecho la compañía, o una o más sociedades del mismo grupo empresarial. Otro podría consistir en la concesión de una excepción contra quien demande judicialmente el cumplimiento de una obligación originada mediante un abuso de la forma societaria ${ }^{100}$; o como un incidente con ocasión de cualquier procedimiento en que ello resulte necesario para obtener la debida protección de una persona a quien se ha buscado perjudicar injustamente ${ }^{101}$.

\section{Algunas propuestas a mOdo de CONCLUSión}

1. Cuando se afirma que una sociedad goza de personalidad jurídica lo que se quiere es poner de manifiesto que el ordenamiento trata de manera especial ese fenómeno de asociación de personas y que prescinde de los integrantes del grupo para configurar una única titularidad de relaciones jurídicas que se atribuye propiamente a la organización o ente creado. El reconocimiento de la personalidad jurídica determina, en principio, la diferenciación del patrimonio social y los patrimonios individuales de quienes la conforman, así como de las relaciones jurídicas sociales y las relaciones individuales de los socios, dando origen a la separación jurídica entre la sociedad y los socios. Esta separación instrumental es necesaria para que la organización que surge del contrato social pueda desarrollar sus objetivos, sin embargo, aquella -tal como está concebida hoy- se torna ineficaz si no va de la mano de la limitación de responsabilidad, pues solo las sociedades que gozan de este privilegio dispondrán verdaderamente de una protección económica respecto del patrimonio de los socios ${ }^{102}$.

2. La limitación de responsabilidad es un fenómeno posterior a la creación de las sociedades y de la personalidad jurídica. Surge de la mano de las sociedades anónimas y se ha extendido a otras figuras con el paso del tiempo, lo que nos obliga a reflexionar sobre una posible extensión de la limitación de responsabilidad a otros tipos societarios. Para ello debemos considerar que todas las sociedades representan un tipo de inversión económica y que no existen fundamentos plausibles en la actualidad para brindar este privilegio a ciertos tipos societarios y negárselo a otros.

${ }^{100}$ Por ejemplo, véase sentencia en juicio Scharfstein S. A. con Browne Keeling y Cía. Ltda. y Emparanza Paiva, Margarita Juliana.

${ }^{101}$ En este sentido, en el juicio ordinario por cobro de pesos Proinvest Promotora de Inversiones S.A. con Trends Ingeniería S.A. y Datun Chile S.A., llevado ante la Corte de Apelaciones de Santiago.

102 Díaz Moreno, A., "Las sociedades mercantiles”, en Lecciones de derecho mercantil, Jiménez Sánchez, Guillermo (Coord.), 6a edición, Ed. Tecnos, Madrid, 2000, p. 162. En el mismo sentido, Baeza Ovalle, G.,

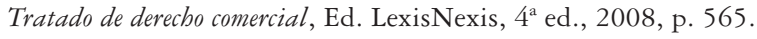


3. Basado en lo anterior, la autonomía patrimonial de la personalidad jurídica no implica responsabilidad limitada, se trata de dos instituciones diferenciadas. El establecimiento de la responsabilidad limitada ha mutado los fundamentos y elementos que se tuvieron en mente en el reconocimiento inicial de la personalidad jurídica en concordancia con la noción societaria, lo que obliga a la revisión de esta noción ${ }^{103}$.

4. El levantamiento del velo ha constituido un mecanismo muy difundido para poner en jaque la noción de limitación de responsabilidad limitada, más que de la personalidad jurídica, pues lo que se pretende con aquella es romper el hermetismo patrimonial de las sociedades que gozan de aquella. La debilidad intrínseca de esta doctrina reside en la dificultad para formular un criterio rector que indique en qué casos se puede prescindir de esta estructura y en cuáles no. Esta cuestión es fuente de incertidumbre que amenaza el principio de seguridad jurídica, por lo que se admite su aplicación de manera excepcional ${ }^{104}$.

5. Lo anterior nos lleva a la necesidad de reformular la noción de personalidad jurídica en las sociedades considerando, entre otros elementos, la posibilidad de extender la limitación de responsabilidad limitada, pues en la medida que se posean conceptos claros sobre el valor instrumental de aquella y la función que el instituto está llamado a cumplir, carece de sentido sostener el pretendido carácter excepcional de los casos en que puede aplicarse esta técnica. En este camino, podrían crearse normas de imputación de responsabilidad a socios, administradores o directivos en general frente a supuestos concretos; o bien crear acciones o excepciones directas en casos de abusos de la personalidad societaria ${ }^{105}$.

\section{BIBLIOGRAFÍA}

Aguad Deik, A., "Los límites de la personalidad jurídica. La doctrina del levantamiento del velo", en Estudios sobre reformas al código civil y código de comercio. Teoría de los riesgos. Reformas al derecho internacional privado. El abuso de la personalidad jurídica. La protección de la apariencia en el derecho civil. Ed. Jurídica de Chile, Santiago de Chile, 2002.

Aguirre, H. A., El debate sobre la personalidad jurídica de las sociedades de personas en Italia, disponible en http://nvabogados.com.ar/el\%20debate\%20sobre $\% 201 \mathrm{l} \% 20$ personalidad $\% 20$ juridica $\% 20$ de $\% 201$ las $\% 20$ sociedades $\% 20$ en $\% 20$ italia.pdf

Bercovitz Rodríguez-Cano, A., La sociedad de responsabilidad limitada, Ed. Thomson Aranzadi, Navarra, 2006.

Boldó Roda, C., Levantamiento del velo y persona jurídica en el derecho privado español, Ed. ThomsonAranzadi, Navarra, $4^{a}$ edición, 2006.

${ }^{103}$ De Castro y Bravo, ob. cit., p. 237.

${ }^{104}$ Ello ha sido criticado desde diversas perspectivas, la más sustancial liga con las posturas de Ascarelli y Galgano, quienes cuestionan esta tesis por utilizar una ficción para contrarrestar otra: la de persona jurídica. Véase: Capilla Roncero, ob. cit., p. 70.

${ }^{105}$ Lojendio Osborne, I.; Núñez Lozano, P., ob. cit., p. 19. 
Boquera Matarredona, J., "La sociedad unipersonal de responsabilidad limitada", en Estudios de Derecho mercantil, Ed. Civitas, Madrid, 1996.

Calvo Vidal, I., La persona jurídica societaria, Consejo General del Notariado, Madrid, 2011.

Capilla Roncero, F., La persona jurídica: funciones y disfunciones, Ed. Tecnos, Madrid, 1984.

Corral Talciani, H., y Díaz Villalobos, J., (Editores), Las empresas individuales de responsabilidad limitada, Cuadernos de extensión jurídica, Universidad de los Andes, 2004.

Davis, A., Sociedades civiles y comerciales, Gibbs, C., Editor, Santiago, 1963.

De Castro y Bravo, F., La persona jurídica, Ed. Civitas, Madrid, 1981.

De los Mozos, J. L., "La evolución del concepto de persona jurídica en el derecho español”, en Derecho civil, método, sistemas y categorías jurídicas, Ed. Civitas, Madrid, 1988.

Díaz Moreno, A., "Las sociedades mercantiles", en Jiménez Sánchez, G. (Coord.), Lecciones de derecho mercantil, $6^{\circ}$ edición, Ed. Tecnos, Madrid, 2000.

Diez Picazo, L., Fundamentos de Derecho Civil Patrimonial, Vol. I, Ed. Tecnos, Madrid, 1986, $2^{\circ}$ edición.

Ferrara, F., Teoría de la persona jurídica, Ed. Comares, España, 2006.

GALGANO, F., Las instituciones de la economía capitalista. Sociedad anónima, Estado y clases sociales (traducción de Manuel Broseta Pont y Carmen Alborch Bataller), Fernando Torres - Editor, SA., Valencia, 1980.

Hierro Anibarro, S., El origen de la sociedad anónima en España, Ed. Tecnos, Madrid, 1998.

Hugo Richard, E., "Personalidad jurídica. Inoponibilidad", en Nissen, R.; Pardini, M., y Vitolo, D., (directores), Responsabilidad y abuso en la actuación societaria, Ed. Ad Hoc, Buenos Aires, 2002.

IRURETA Uriarte, P., "Aplicaciones de la doctrina del levantamiento del velo corporativo", en Actas de las II jornadas de derecho de la empresa, Facultad de Derecho de la Pontificia Universidad Católica de Chile, Santiago, 2005.

Jaramillo Herrera, L., "Desestimación de la personalidad jurídica en el derecho societario colombiano", en Revista CES derecho, Vol. 2, No 2, julio-diciembre 2011.

JEQUiER, E., "Unipersonalidad y sociedad con un solo socio; alcances de su reconocimiento en la estructura dogmática del derecho chileno”, en Revista Ius et Praxis, Año 17, No 2, 2011.

Lara Aguayo, E., "Descorriendo el velo corporativo de la empresa”, en Jornadas Chileno-Uruguayas de derecho comercial, Ed. Librotecnia, Santiago, 2011.

Lara Aguayo, E., "La crisis del concepto de persona jurídica y el levantamiento del velo", en Gaceta Jurídica No 314, Santiago, 2007

Lazo González, P., "Limitación de la responsabilidad: Bases romanas de un dogma iusprivatista", en Revista de derecho Universidad Austral de Chile, Vol. XXV - julio 2012.

Lojendio Osborne, I.; Núñez Lozano, P., "Las sociedades mercantiles”, en Jiménez Sánchez, G., Derecho mercantil I, Ed. Marcial Pons, 2010.

López Díaz, P., La doctrina del levantamiento del velo y la instrumentalización de la personalidad jurídica, Ed. LexisNexis, Santiago de Chile, 2003.

López Fernández, D., La empresa como unidad económica, Ed. Abeledo Perrot-LegalPublishing, Santiago de Chile, 2010.

Lyon Puelma, A., Personas jurídicas, abuso de la forma, gobierno corporativo y responsabilidad, derechos y obligaciones de los miembros, divisiones, fusiones, conflictos de interés, control. Ed. Universidad Católica de Chile, Santiago, 2004.

Lyon Puelma, A., Personas jurídicas, Ed. Universidad Católica de Chile, Santiago de Chile, 2002.

MArcos, F., "La responsabilidad limitada", en Instituto de empresa, 2002, disponible en http:// profesores.ie.edu/fmarcos/Publicaciones_archivos/La\%20Responsabilidad\%20limitada.pdf

Miranda Ostegaard, D., "El traspaso del velo corporativo en los convenios concursales", en Revista de derecho de la empresa, $\mathrm{N}^{\circ}$ 9, enero-marzo 2007.

Molina Sandoval, C., "Apostillas sobre la personalidad jurídica societaria en el derecho argentino", en Revista e-mercatoria, vol. 3, No 1, 2004. 
Oviedo Albán, J., "La personificación jurídica societaria en el Derecho colombiano”, disponible en http://www.usa.edu.co/investigacion-derecho/edicion 1/La-Personificaci\%C3\%B3nJur\%C3\%ADdica-Societaria-en-el-Derecho-Colombiano.txt.pdf.

Paz-Ares Rodríguez, C., "Atributos y límites a la personalidad jurídica”, en Uría R., Menéndez, A. (Coord.), Curso de derecho mercantil I, Ed. Civitas, Madrid, 1999.

Puelma Acorssi, A., Sociedades, Ed. Jurídica de Chile, Santiago de Chile, 2006.

PUGA Vial, J. E., La sociedad anónima y otras sociedades por acciones en el Derecho chileno y comparado, Ed. Jurídica de Chile, Santiago, 2011.

PRIETO, P., "La personalidad jurídica de las sociedades civiles: contra la resolución de la DGRN de 31 de marzo de 1997”, en La Ley, Revista Jurídica española de doctrina, jurisprudencia y bibliografía, $\mathrm{N}^{\circ}$ 4, Madrid, 1997.

Quesada Sánchez, A. J., “Análisis histórico-jurídico del artículo 1669 del ‘Código Civil’ español”, en Revista de derecho de la Pontificia Universidad Católica de Valparaíso, XXXII, $1^{\circ}$ semestre 2009.

Quesada Sánchez, A. J., Las sociedades civiles sin personalidad jurídica en el ordenamiento español, Ruiz-Rico Ruiz, J. (Director), Tesis doctoral, Universidad de Málaga, 2003.

Quesada Sánchez, A., "La personificación de las sociedades civiles. Análisis histórico-jurídico del artículo 1669 del "Código Civil" español", en Revista de Derecho de la Pontificia Universidad Católica de Valparaíso, Vol. 32, Valparaíso, Chile, 2009.

Reyes Villamizar, F., SAS. La sociedad por acciones simplificada, Ed. Legis, 2010 ( $2^{\circ} \mathrm{ed}$.).

SÁnchez Calero, F., Instituciones de derecho mercantil (17º ed.), Ed. Edersa, Madrid, 1994.

SÁnchez Calero, F. y Sánchez-Calero Guilarte, J., Instituciones de Derecho Mercantil, Vol. I, $29^{a}$ edición, Thomson-Aranzadi, Navarra, 2006.

Sandoval López, R., Derecho comercial. Sociedades de personas y de capital, tomo I y II, Ed. Jurídica de Chile, Santiago de Chile, 2003

SERICK, R., Apariencia y realidad en las sociedades mercantiles. El abuso de derecho por medio de la persona jurídica, Ed. Ariel, Barcelona, 1958.

SChluter, Wilfre, "El derecho de sociedades en la República Federal de Alemania (1 ra. parte)", en Revista del Derecho Comercial y de las Obligaciones, 1991, pp. 277-286.

Torres Zagal, O., Derecho de sociedades, $3^{\circ}$ edición actualizada, Legal Publishing, Chile, 2008.

Ugarte Vial, J., "Fundamentos y acciones para la aplicación del levantamiento del velo en Chile", en Revista chilena de derecho, vol. 39, N 3, 2012.

VArela Fleckenstein, A., "La doctrina del levantamiento del velo en la jurisprudencia nacional", en Vásquez, M. F. (Coord.), Estudios de derecho comercial. Ed. AbeledoPerrot-LegalPublishing, Santiago de Chile, 2011.

VÁsquez Palma, M. F., Sociedades, Ed. Thomson Reuters, Santiago de Chile, 2013.

Vincent Chuliá, F., Introducción al Derecho mercantil, Tirant lo Blanch, Valencia, 2006.

Zárate, H., "Personalidad jurídica y su desestimación", Facultad de derecho y ciencias sociales y políticas - UNNE, Argentina.

\section{Sentencias}

Excma. Corte Suprema, Inversiones Fabjanovic Ltda. con Comercial Araucaria y otros, Rol 3631 2005, 7 de junio de 2007.

Excma. Corte Suprema, Verónica Fernández Omar contra Sociedad Miguel y Miguelo's Pub Limitada, Rol 7836-2008, 6 de abril de 2009.

Excma. Corte Suprema, Banco Scotiabank Sudamericano con Campodónico Quiroga, Oscar, Rol 604306, 25 de marzo de 2008.

Excma. Corte Suprema, Hernán Bordagara y Vásquez y otros con Mutuos Hipotecarios Santa Fe SA y otras, Rol 1.933-01, 19 de julio de 2001. 
Exсмa. Corte Suprema, "Distribuidora Magallanes Limitada contra Llegar, Andrea", Rol 6.070-09, 11 de noviembre de 2009.

ExсмA. Corte Suprema, Rol No 4.005-02, 13 de agosto de 2003.

ExсмA. Corte Suprema, Rol No 865-2009, 12 de agosto de 2010.

Iltma. Corte de Apelaciones de Concepción, Carlos Mellado Backarzick con Sociedad Administradora de Servicios de Vigilancia Unimarc S.A., Rol No 3.199-05.

Iltma. Corte de Apelaciones de Santiago, Scharfstein S.A. con Browne Keeling y Cía. Ltda. y Emparanza Paiva, Margarita Juliana, Rol 771-2010, 11 enero 2011.

Iltma. Corte de Apelaciones de Punta Arenas, Catrilef Hernández, Salomón y otros con Pesca Cisne S.A.

Iltma. Corte de Apelaciones de Santiago, Proinvest Promotora de Inversiones S. A. con Trends Ingeniería S.A. y Datun Chile S.A.

Iltma. Corte de Apelaciones de Talca, Rol 50-2010, 29 de junio de 2010.

Iltma. Corte de Apelaciones de Talca, Rol 1869-09, 27 de mayo de 2010, revocada por la Corte Suprema, Rol 4192-10, 22 de julio de 2010.

Iltma. Corte de Apelaciones de Talca, Rol 50-2010, 29 de junio de 2010.

Iltma. Corte de Apelaciones de Talca, Rol 1869-09, 27 de mayo de 2010, revocada por la Corte Suprema, 22 de julio de 2010, Rol 4192-10. 